\title{
Electron spectroscopy of ionic liquids: experimental identification of atomic orbital contributions to valence electronic structure
}

Article

Accepted Version

Fogarty, R., Palgrave, R., Bourne, R., Handrup, K., VillarGarcia, I., Payne, D., Hunt, P. and Lovelock, K. R. J. (2019) Electron spectroscopy of ionic liquids: experimental identification of atomic orbital contributions to valence electronic structure. Physical Chemistry Chemical Physics, 21 (35). pp. 18893-18910. ISSN 1463-9076 doi:

https://doi.org/10.1039/C9CP02200G Available at https://centaur.reading.ac.uk/85195/

It is advisable to refer to the publisher's version if you intend to cite from the work. See Guidance on citing.

To link to this article DOI: http://dx.doi.org/10.1039/C9CP02200G

Publisher: Royal Society of Chemistry

All outputs in CentAUR are protected by Intellectual Property Rights law, including copyright law. Copyright and IPR is retained by the creators or other copyright holders. Terms and conditions for use of this material are defined in the End User Agreement. 


\section{www.reading.ac.uk/centaur}

\section{CentAUR}

Central Archive at the University of Reading

Reading's research outputs online 


\title{
Electron spectroscopy of ionic liquids: experimental identification of atomic orbital contributions to valence electronic structure
}

\author{
Richard M. Fogarty, ${ }^{1}$ Robert G. Palgrave,${ }^{2}$ Richard A. Bourne, ${ }^{3}$ Karsten Handrup,${ }^{4}$ Ignacio J. Villar- \\ Garcia, ${ }^{5}$ David J. Payne, ${ }^{5}$ Patricia A. Hunt, ${ }^{1}$ Kevin R. J. Lovelock. ${ }^{6}$ \\ ${ }^{1}$ Department of Chemistry, Imperial College London, UK \\ ${ }^{2}$ Department of Chemistry, University College London, UK \\ ${ }^{3}$ Institute of Process Research and Development, Schools of Chemistry and Chemical and Process \\ Engineering, University of Leeds, UK \\ ${ }^{4}$ MAX IV Laboratory, Lund University, Lund, Sweden \\ ${ }^{5}$ Department of Materials, Imperial College London, UK \\ ${ }^{6}$ Department of Chemistry, University of Reading, UK \\ Contact E-mail: k.r.j.lovelock@reading.ac.uk
}

\begin{abstract}
The atomic contributions to valence electronic structure for 37 ionic liquids (ILs) are identified using a combination of variable photon energy XPS, resonant Auger electron spectroscopy (RAES) and a subtraction method. The ILs studied include a diverse range of cationic and anionic structural moieties. We introduce a new parameter for ILs, the energy difference between the energies of the cationic and anionic highest occupied fragment orbitals (HOFOs), which we use to identify the highest occupied molecular orbital (HOMO). The anion gave rise to the HOMO for 25 of the 37 ILs studied here. For 10 of the ILs, the energies of the cationic and anionic HOFOs were the same (within experimental error); therefore, it could not be determined whether the HOMO was from the cation or the anion. For two of the ILs, the HOMO was from the cation and not from the anion; consequently it is energetically more favourable to remove an electron from the cation than the anion for these two ILs. In addition, we used a combination of area normalisation and subtraction of XP spectra to produce what are effectively XP spectra for individual ions; this was achieved for seven cations and 14 anions.
\end{abstract}

\section{Introduction}

Ionic liquids (ILS), liquids composed entirely of mobile ions, provide a novel environment different from traditional (neutral) molecular liquids or high temperature molten salts. Liquid phase valence electronic structure, i.e. the molecular orbitals (MOs), controls chemical reactivity, electrochemistry and electronic interactions with light. ${ }^{1-3}$ Therefore, IL electronic structure underpins a broad range of potential technologies: electrochemical applications (supercapacitors, fuel cells, photoelectrochemical cells, batteries) ${ }^{4-7}$ photochemical applications, ${ }^{6-9}$ nuclear fuel processing, ${ }^{10}$ deconstruction of lignocellulosic biomass, ${ }^{11}$ and gas separation/capture/storage ${ }^{12,13}$. Knowledge of the energies and composition of the highest occupied $\mathrm{MO}$ (HOMO) and valence MOs near in energy to the HOMO is vital for understanding any process that involves removal of an electron from the IL. For example, electrochemical oxidation and reduction of ILS are crucial for understanding electrochemical stability; ${ }^{14,}{ }^{15}$ greater oxidative and reductive stability can lead to better supercapacitors ${ }^{16}$. In addition, experimental data of the valence electronic structure is of primary use for validation of electronic structure calculations. To provide a valid test of calculations, experimental data needs to be independent of the calculations, i.e. information from experiments must be gained without input of calculations.

A molecular liquid contains only one constituent, the molecule. The solvation environment in a molecular liquid is broadly always the same; a molecule is surrounded by other molecules of the same kind. ILs contain at least two constituents: a cation and an anion. The cation has a different solvation environment to the anion, i.e. there are different solvation environments around each ion. Therefore, 
determining the correct relative energies for the anionic and cationic valence MOs of an IL is challenging. There are many combinations of IL cations and anions, giving a challenging range of different valence electronic structures. Both ions in an IL will give a highest occupied fragment orbital (HOFO), one of which will also be the IL HOMO. Using a combination of experiments and calculations, in some ILs the cation HOFO has been identified as the system HOMO, ${ }^{17-20}$ a result that might go against some researchers' chemical intuition. Overall, understanding IL valence electronic structure is expected to be significantly more difficult than understanding molecular liquid valence electronic structure.

X-ray and ultraviolet spectroscopy are used to study the valence electronic structure of condensed matter. The techniques used include: X-ray photoelectron spectroscopy (XPS), ultraviolet photoelectron spectroscopy (UPS), resonant Auger electron spectroscopy (RAES), X-ray emission spectroscopy (XES) and inverse photoelectron spectroscopy (IPES). ${ }^{21-25}$ Most X-ray spectroscopy techniques require ultra-high vacuum conditions. X-ray spectroscopy is relatively straightforward for ILs, unlike for aqueous systems, ${ }^{24-28}$ due to their very low volatility. ${ }^{21,29}$ Experimentally, X-ray source electron-detection techniques can be used to determine energies and atom-based contributions to liquid phase MOs.

X-ray photoelectron spectroscopy (XPS), the most commonly used X-ray technique to study the valence MOs, involves using electromagnetic radiation to induce the ejection of an electron from a particular (core or valence) orbital and measuring the kinetic energy, $E_{\mathrm{K}}$, of the ejected electron to determine the electron binding energy, $E_{\mathrm{B}}$, of the probed orbital (Figures $1 \mathrm{~b}$ and $1 \mathrm{c}$ ). Valence XPS involves the removal of a valence electron, leaving the atom in a $1 h_{\vee}$ final state, and gives rise to peaks at constant $E_{\mathrm{B}}$ (referenced to the Fermi level, $E_{\mathrm{F}}$ ). A single $h v$ XPS source can provide an experimental measure of valence $M O E_{B}$. Therefore, valence XP spectra recorded at a single $h v$ have been used to validate calculated $\mathrm{MO}$ energies for a number of ILs. ${ }^{17,} 19,30-32$

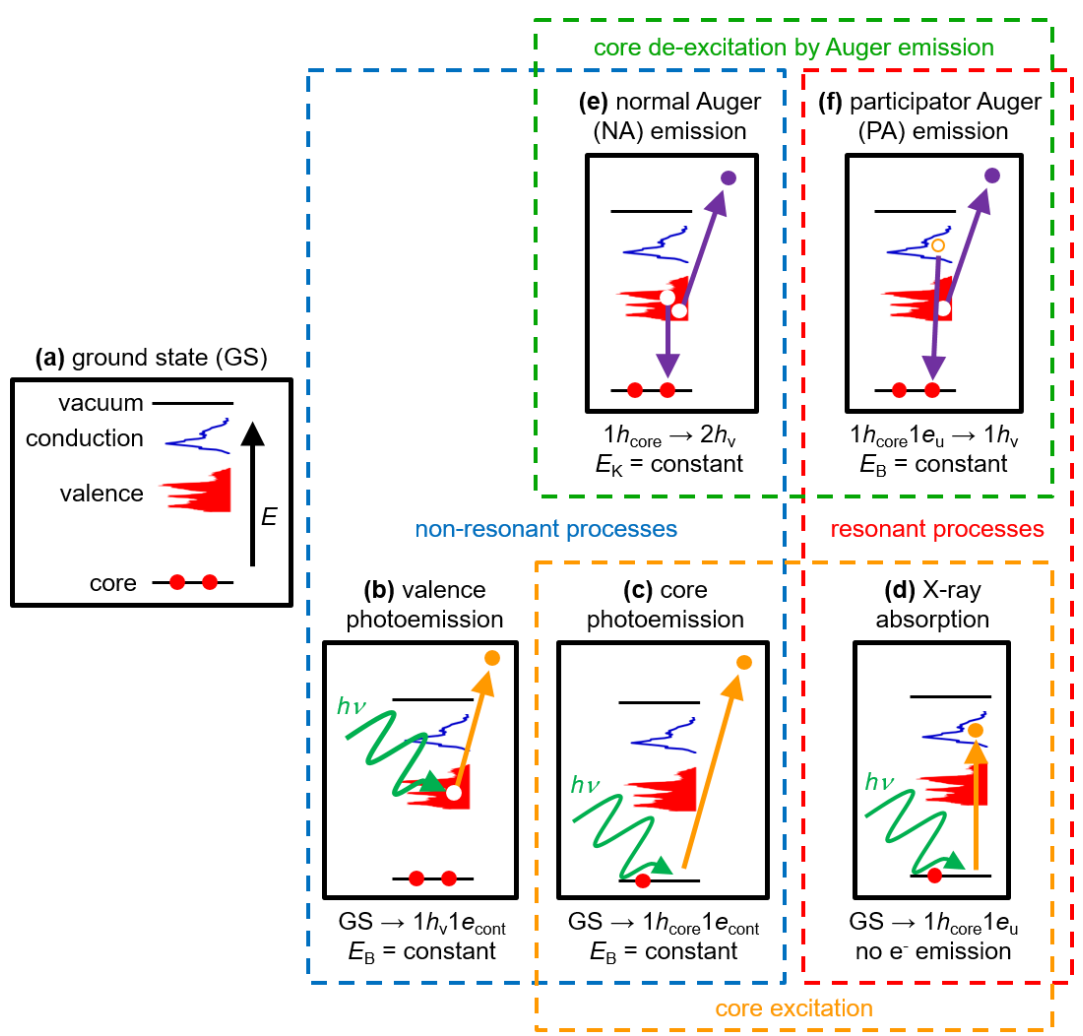

Figure 1. Sketches explaining the different electron dynamics events featured in this article. The contents of each dashed box represent different collective events: blue dashed box = non-resonant processes, orange dashed box $=$ core excitation (both non-resonant and resonant), red dashed box = 
resonant processes (i.e. involving core excitation), green dashed box = core de-excitation by Auger emission. A simplified ground state (containing only one core level) is shown in (a). The text at the bottom of each sketch gives the initial state and the final state of each event. For valence and core photoemission, $1 e_{\text {cont }}$ refers to an electron in the continuum (vacuum). For X-ray absorption, $1 e_{u}$ refers to an electron in a previously unoccupied conduction molecular orbital.

Experimental identification of the atomic orbitals (AOs) that contribute to MOs for ILs, e.g. whether a valence $\mathrm{MO}$ originates primarily from the cation or the anion, has proven extremely challenging for ILs. Compared to many of the samples traditionally studied using XPS, e.g. metal oxides, ILs have a relatively large number of different elements and therefore a relatively large number of different contributing AOs.

Valence MOs for ILs can potentially be identified from single $h v$ valence XP spectra using a visual fingerprint method (i.e. measuring valence XP spectra for a number of ILs, identifying peaks common to structurally similar ILs and using this information to identify other peaks). Area normalisation to aid visual interpretation of core level XP spectra has been successfully used for a range of ILs, with the focus on identifying the different $\mathrm{C}$ 1s electronic environments for ILs with common structural features. ${ }^{33,34}$ However, such a visual fingerprint method has not been demonstrated for identification of valence MOs for ILs to date, most likely due to the relatively complex valence XP spectra of ILs and the relatively small number of ILs studied using valence XPS.

Variable source $h v$ valence XPS has been used to obtain information on the atomic (AO) contributions to MOs from changes in relative peak intensities by using the Gelius method and AO photoionisation cross-sections (see ESI Section 6 for more details). ${ }^{35-37}$ A combination of variable $h v$ valence XPS and density functional theory (DFT) calculations have been used to investigate the valence MOs of 15 ILs, including a range of different cations $\left(\left[C_{n} C_{1} I m\right]^{+}=1\right.$-alkyl-3-methylimidazolium, $\left[C_{n} C_{1} \text { Pyrr }\right]^{+}=1$-alkyl-1methylpyrrolidinium) and anions $\left(\mathrm{Cl}^{-}=\right.$chloride, $\left[\mathrm{BF}_{4}\right]^{-}=$tetrafluoroborate, $\left[\mathrm{N}(\mathrm{CN})_{2}\right]^{-}=$dicyanamide, $\left[\mathrm{TfO}^{-}=\text {trifluoromethylsulfonate, }\left[\mathrm{NTf}_{2}\right]^{-}=\text {bis[(trifluoromethane)sulfonyl]imide }\right)^{20,38,39}$; however, insufficient experimental information was available to draw conclusions solely from experimental data. Soft XES has been used to experimentally identify $A O$ contributions to MOs for three $\left[C_{4} C_{1} I m\right][A]$ ILs (where $[\mathrm{A}]^{-}$was $\left[\mathrm{PF}_{6}\right]^{-}=$hexafluorophosphate, $\left[\mathrm{TfO}^{-}\right.$and $\left.\left[\mathrm{NTf}_{2}\right]^{-}\right){ }^{18,19} \mathrm{~A}$ drawback of this method is that matching of $X E$ energies to $M O E_{B}$ can prove challenging.

Resonant Auger electron spectroscopy (RAES) is an element-specific, and potentially site-specific, technique to probe the valence MOs (and the conduction MOs). RAES has been used to study the valence electronic structure of the condensed phase for: ionic crystals (e.g. $\mathrm{CaF}_{2}{ }^{40} \mathrm{BN}^{41} \mathrm{Na}\left[\mathrm{NO}_{3}\right]^{42,43}$ ), a range of small organic molecules (nitrogen heterocycles, ${ }^{44}$ furan and pyrrole, ${ }^{45,46}$ ethylene and cyclohexane,${ }^{47}$ benzene, ${ }^{48}$ acrylonitrile ${ }^{49}$ ), a thiophene oligomer, ${ }^{50}$ polymers ${ }^{51-53}$, proteins, ${ }^{54}$ DNA, $, 55,56$ water, ${ }^{57}$ perovskite, ${ }^{58}$ and ions in aqueous solution ${ }^{59-63}$, but not for ILs to the best of our knowledge.

For RAES, X-rays are absorbed, leading to core level excitation of a specific core orbital on a specific element at a specific photon energy. An electron is promoted to a previously unoccupied conduction $\mathrm{MO}$, forming a one-hole (core) one-electron (previously unoccupied) intermediate state ( $\left.1 h_{\text {core }} 1 e_{u}\right)$ (Figure 1d); this intermediate has the same charge as the ground state. The unstable core hole is filled (i.e. de-excited) by an electron from a higher energy level, leading to radiative emission (X-ray fluorescence) or radiationless emission of an Auger electron (Auger emission). For lighter elements (which ILs are generally composed of) Auger emission is favoured. ${ }^{64}$ Three types of resonant Auger emission can occur: participator Auger emission (Figure 1f), spectator Auger emission and resonant normal Auger emission. These different processes can give complementary information on the valence (and/or conduction) MOs. The focus of this article is valence electronic structure, so we only explain the theory behind participator Auger emission. 
For participator Auger emission, the core hole is filled by the same $1 e_{\mathrm{u}}$ that was initially excited to a conduction $\mathrm{MO}$, and $1 e_{v}$ is simultaneously emitted. Participator Auger transitions give the same $1 h_{v}$ (valence) final state as direct photoemission. Generally, participator Auger emission gives electrons with approximately the same $E_{\mathrm{K}}$ (and therefore, $E_{\mathrm{B}}$ ) as those from direct photoemission, ${ }^{45}$ called the resonant Auger Raman effect, ${ }^{42}$ leading to an enhancement in intensity, under resonant conditions, of peaks due to valence XPS.

The probabilities of participator Auger transitions are controlled by MO localisation, i.e. only those MOs located near to the core-hole can give participator Auger electron emission. ${ }^{46-48}$ These probabilities can be used to probe both the valence MOs (and the conduction MOs). The relative intensity of peaks due to two different participator Auger transitions at the same photon energy (i.e. the same resonant $1 e_{u}$ ) is governed by the localisation of the two effectively competing $1 e_{v}$ near to the core-hole. Hence, the observation of peaks due to participator Auger transitions can be used to identify $1 e_{v}$ (i.e. valence MOs) that are located near to the atom with the core-hole. Therefore, participator Auger RAES is an element-specific, and often site-specific, method to identify which atoms significantly contribute AOs to particular MOs. Participator Auger RAES is especially powerful when a sample is composed of atoms of the same element in significantly different electronic environments; for ILs this power allows cationic and anionic contributions (for a specific element) to MOs to be distinguished. In addition, matching RAES energies to $M O E_{B}$ is straightforward, an advantage over XES.

In this article, we identify atomic contributions to IL valence electronic structure using experimental methods, without the aid of calculations. The 37 ILs studied in this paper are given in ESI Table S1; how the ILs were chosen is given in ESI Section 1. For seven ILs, MO identification was achieved using a combination of variable $h v$ XPS (Section 3.1) and RAES (Section 3.2). RAES was particularly effective for identification of cationic and anionic nitrogen atom contributions to the valence MOs. Using a combination of the MO identifications provided by variable $h v$ XPS and RAES, the fingerprint method and the area subtraction method, MO identification was achieved for a further 30 ILs (Section 3.3 and Section 3.4). The fingerprint and area subtraction methods are explained more in detail in ESI Section 8 to ESI Section 11. For all 32 different ions studied here ion HOFOs were identified, and for all 37 ILS the HOMO was identified (Section 3.5 and Section 3.6). In addition, two different measures of the energy difference between the cationic and anionic HOFOs were determined (Section 3.6). 


\section{Experimental}

Details of IL synthesis are given in the ESI Section 1.

Laboratory-based XPS was carried out using two separate Thermo K-alpha spectrometers utilising AI $K \alpha$ radiation $(h v=1486.6 \mathrm{eV}) .{ }^{65,66}$ Valence XP spectra (with lower $h v$ than $1486.6 \mathrm{eV}$ ) and all RAES data were collected at MAX-lab (beamline 1311). Further details for all three experimental set-ups are given in the ESI Section 2.

Details on data analysis (e.g. fitting XP spectra) are provided in the ESI Section 4 to ESI Section 12 . The purity of the ILs studied here is demonstrated in the ESI Section 13. 


\section{Results}

A summary of the results for all 37 ILs studied here is given in Table 3 . Table 1 and Table 2 give details, for $\left[\mathrm{C}_{4} \mathrm{C}_{1} \mathrm{Im}\right][\mathrm{SCN}]$ and $\left[\mathrm{C}_{8} \mathrm{C}_{1} \mathrm{Im}\right] \mathrm{Cl}$ respectively, of the experimental spectral features, provide qualitative observations and give the experimentally-determined atomic contributions to each peak. ESI Table S8 to ESI Table S12 give details for the other five ILs studied here using variable $h v$ XPS and RAES. The method used to assign component labels for the seven ILs studied with RAES is given in the ESI Section 4.

\subsection{Variable $h v$ XPS}

Six of the ILs studied here were investigated using variable $h v$ XPS. [ $\left.\mathrm{C}_{8} \mathrm{C}_{1} \mathrm{Im}\right] \mathrm{Cl}, \quad\left[\mathrm{C}_{4} \mathrm{C}_{1} \mathrm{Im}\right][\mathrm{SCN}]$, $\left[\mathrm{P}_{6,6,6,14}\right]\left[\mathrm{NO}_{3}\right],\left[\mathrm{N}_{4,1,1,0}\right]\left[\mathrm{HSO}_{4}\right],\left[\mathrm{C}_{8} \mathrm{C}_{1} \mathrm{Im}\right]\left[\mathrm{NTf}_{2}\right]$ and $\left[\mathrm{N}_{2,2,1,0}\right][\mathrm{TfO}]$ showed valence XP spectra with different relative peak areas at high $h v$ (in this article $h v=1486.6 \mathrm{eV}$ ) and low $h v$ (in this article 129 $\mathrm{eV}<h v<200 \mathrm{eV}$ ). XP spectra recorded at high and low $h v$ are shown in Figure 2 for $\left[\mathrm{C}_{4} \mathrm{C}_{1} 1 \mathrm{~m}\right][\mathrm{SCN}]$ and $\left[C_{8} C_{1} I \mathrm{~m}\right] \mathrm{Cl}$, and in ESI Figure S59 for the other ILs. At $h v=165.0 \mathrm{eV}$ for all seven elements of importance here $(\mathrm{C}, \mathrm{N}, \mathrm{O}, \mathrm{F}, \mathrm{P}, \mathrm{S}, \mathrm{Cl})$, the $\mathrm{s}$ and $\mathrm{p}$ orbital photoionisation cross-sections are of similar magnitude (ESI Table S5 and ESI Figure S10a). At $h v=1486.6 \mathrm{eV}$ for all seven elements (C, N, O, F, P, $\mathrm{S}, \mathrm{Cl}$ ), the $\mathrm{s}$ orbital photoionisation cross-sections are larger than the $\mathrm{p}$ orbital photoionisation crosssections (ESI Table S5 and ESI Figure S10a), particularly for the $2^{\text {nd }}$ row elements (C, N, O, F). Comparing high and low $h v$ valence XP spectra for these six ILs, the features at $E_{\mathrm{B}}>12 \mathrm{eV}$ were more intense, relative to the features at $E_{\mathrm{B}}<12 \mathrm{eV}$, for the high $h v$ valence XP spectra. Therefore, for the features with $E_{\mathrm{B}}>\sim 12 \mathrm{eV}, \mathrm{s}$ AOs are the primary contributors to the MOs and for the features at $0 \mathrm{eV}<E_{\mathrm{B}}<$ $\sim 12 \mathrm{eV}, \mathrm{p}$ AOs are the primary contributors to the MOs.

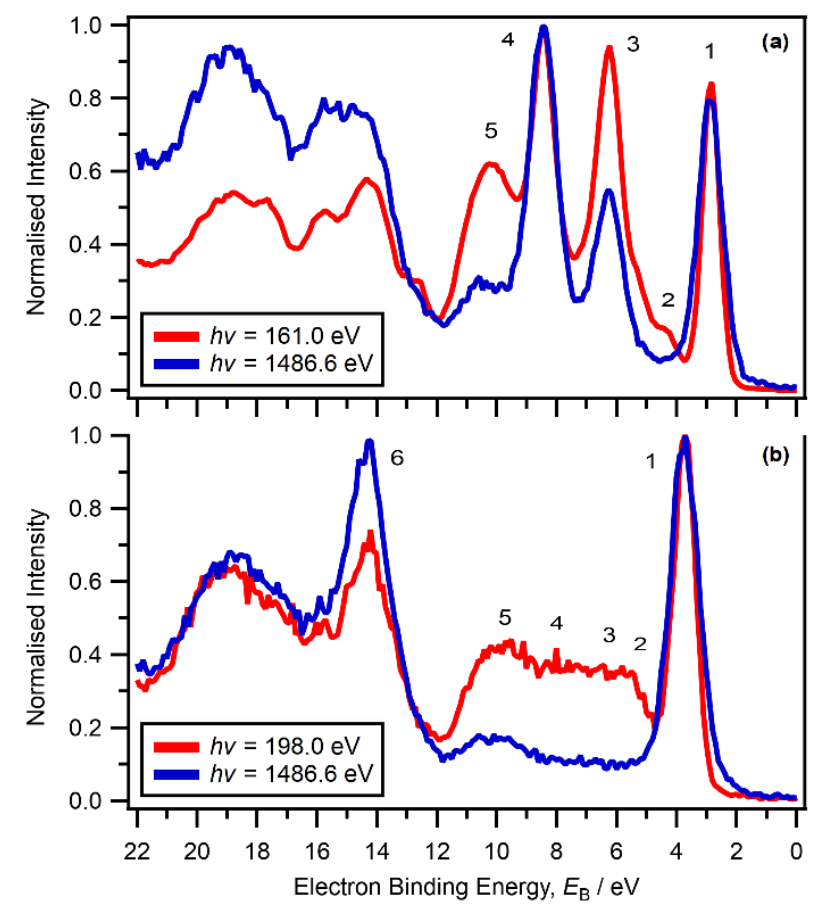

Figure 2. Variable $h v$ valence XP spectra for: (a) $\left[\mathrm{C}_{4} \mathrm{C}_{1} \mathrm{Im}\right][\mathrm{SCN}]$ at $h v=1486.6 \mathrm{eV}$ and $h v=161.0 \mathrm{eV}$ and $(\mathrm{b})\left[\mathrm{C}_{8} \mathrm{C}_{1} \mathrm{Im}\right] \mathrm{Cl}$ at $h v=1486.6 \mathrm{eV}$ and $h v=198.0 \mathrm{eV}$. All valence XP spectra were charge referenced as given in Table S3. The areas of all valence XP spectra in both graphs are normalised to the area of the most intense component in the region $0 \mathrm{eV}<E_{\mathrm{B}}<12 \mathrm{eV}$. The numbers on each graph represent component labels. 
For $\left[\mathrm{C}_{4} \mathrm{C}_{1} \mathrm{Im}\right][\mathrm{SCN}]$, valence XP spectra were recorded at two different photon energies, $h v=1486.6$ $\mathrm{eV}$ and $h v=161.0 \mathrm{eV}$ (Figure 2a). The areas of components 1 and 4 decreased (relative to components 2,3 and 5) with decreasing $h v$. At $h v=1486.6 \mathrm{eV}$, the photoionisation cross-section for $\mathrm{S} 3 p$ is $\sim 50$ times greater than that for $C 2 p$ and $\sim 12$ times greater than that for $N 2 p$ (ESI Section 6 ). ${ }^{37}$ The ratio of $S 3 p$ to $C 2 p$ (and S $3 p$ to $N 2 p$ ) photoionisation cross-sections decreases significantly between $h v=$ $1486.6 \mathrm{eV}$ and $h v=165.0 \mathrm{eV}$ (ESI Section 6 and ESI Figure S10b). Therefore, the relative intensity of components with large S $3 p$ AO contributions is expected to decrease with decreasing $h v$ (relative to other components with mainly C $2 p$ or $\mathrm{N} 2 p$ AO contributions). Therefore, it can be concluded that $S$ $3 p$ AOs contributed significantly to the MOs that gave rise to components 1 and 4 (Figure 2a). Furthermore, it can be concluded that either/both N $2 p$ and C $2 p$ AOs contributed significantly to components 2,3 and 5 .

Table 1. Component electron binding energies, $E_{B}$, for $\left[C_{4} C_{1} I m\right][S C N]$ and experimentally-determined atomic orbital contributions to valence electronic structure (see Figure $2 \mathrm{a}$ for component labels)

\begin{tabular}{|c|c|c|c|}
\hline Component & $\begin{array}{l}\text { Electron binding } \\
\text { energy, } E_{\mathrm{B}} / \mathrm{eV}\end{array}$ & $\begin{array}{l}\text { Atomic orbital contributions } \\
\text { to valence molecular orbitals } \\
\text { determined using variable } h v \\
\text { XPS and the fingerprint } \\
\text { method }\end{array}$ & $\begin{array}{l}\text { Atomic orbital contributions } \\
\text { to valence molecular orbitals } \\
\text { determined using RAES }\end{array}$ \\
\hline 1 & $\sim 3$ & $S_{\text {anion }} 3 p$ & $N_{\text {anion }}$ \\
\hline 2 & $\sim 5$ & $\mathrm{~N}_{\text {cation }} 2 \mathrm{p}$ and/or $\mathrm{C}_{\text {cation }} 2 \mathrm{p}$ & $\mathrm{N}_{\text {cation, }} \mathrm{C}$ \\
\hline 3 & $\sim 6.5$ & $\mathrm{~N} 2 \mathrm{p}$ and/or C $2 \mathrm{p}$ & $\mathrm{N}_{\text {cation, }} \mathrm{N}_{\text {anion }}, \mathrm{C}$ \\
\hline 4 & $\sim 8.5$ & $S_{\text {anion }} 3 p$ & $N_{\text {anion }}$ \\
\hline 5 & $\sim 10$ & $\mathrm{~N}_{\text {cation }} 2 \mathrm{p}$ and/or $\mathrm{C}_{\text {cation }} 2 \mathrm{p}$ & $\begin{array}{l}\text { Spectator Auger } \\
\text { contributions potentially } \\
\text { observed; no conclusions can } \\
\text { be drawn using participator } \\
\text { Auger transitions. }\end{array}$ \\
\hline
\end{tabular}

Table 2. Component electron binding energies, $E_{\mathrm{B}}$, for $\left[\mathrm{C}_{8} \mathrm{C}_{1} \mathrm{Im}\right] \mathrm{Cl}$ and experimentally-determined atomic orbital contributions to valence electronic structure (see Figure $2 \mathrm{~b}$ for component labels)

\begin{tabular}{|c|c|c|c|}
\hline Component & $\begin{array}{l}\text { Electron binding } \\
\text { energy, } E_{\mathrm{B}} / \mathrm{eV}\end{array}$ & $\begin{array}{l}\text { Atomic orbital contributions } \\
\text { to valence molecular orbitals } \\
\text { determined using variable } h v \\
\text { XPS and the fingerprint } \\
\text { method }\end{array}$ & $\begin{array}{l}\text { Atomic orbital contributions } \\
\text { to valence electronic } \\
\text { structure determined using } \\
\text { RAES }\end{array}$ \\
\hline 1 & $\sim 3.7$ & $\mathrm{Cl} 3 p$ & \\
\hline 2 & $\sim 5$ & $\mathrm{~N}_{\text {cation }} 2 \mathrm{p}$ and/or $\mathrm{C}_{\text {cation }} 2 \mathrm{p}$ & $\mathrm{N}_{\text {cation }}$ \\
\hline 3 & $\sim 6$ & $\mathrm{~N}_{\text {cation }} 2 \mathrm{p}$ and/or $\mathrm{C}_{\text {cation }} 2 \mathrm{p}$ & $\mathrm{N}_{\text {cation }}$ \\
\hline 4 & $\sim 8$ & $\mathrm{~N}_{\text {cation }} 2 \mathrm{p}$ and/or $\mathrm{C}_{\text {cation }} 2 \mathrm{p}$ & \\
\hline 5 & $\sim 10$ & $\mathrm{~N}_{\text {cation }} 2 \mathrm{p}$ and/or $\mathrm{C}_{\text {cation }} 2 \mathrm{p}$ & \\
\hline 6 & $\sim 14.3$ & $\mathrm{Cl} 3 \mathrm{~s}$ & $\begin{array}{l}\text { Spectator Auger } \\
\text { contributions potentially } \\
\text { observed; no conclusions can } \\
\text { be drawn using participator } \\
\text { Auger transitions. }\end{array}$ \\
\hline
\end{tabular}

Valence XP spectra for $\left[\mathrm{C}_{8} \mathrm{C}_{1} 1 \mathrm{~m}\right] \mathrm{Cl}$ were recorded at two different photon energies, $h v=1486.6 \mathrm{eV}$ and $h v=198.0 \mathrm{eV}$ (Figure $2 \mathrm{~b}$ ). For $\left[\mathrm{C}_{8} \mathrm{C}_{1} \mathrm{Im}\right] \mathrm{Cl}$, the areas of components 2 to 5 (at $5 \mathrm{eV}<E_{\mathrm{B}}<12 \mathrm{eV}$ ) 
increased (relative to component 1 at $E_{\mathrm{B}}=3.7 \mathrm{eV}$ ) with decreasing $h v$ (Figure $2 \mathrm{~b}$ ). The ratio of $\mathrm{Cl} 3 \mathrm{p}$ to $\mathrm{C} 2 \mathrm{p}$ (and $\mathrm{Cl} 3 p$ to $\mathrm{N} 2 \mathrm{p}$ ) photoionisation cross sections decrease significantly with decreasing $h v$ (ESI Section 6 and ESI Figure S10c). Therefore, $\mathrm{Cl} 3 p$ AOs contributed significantly to the MOs of component 1. Furthermore, $\mathrm{N} 2 \mathrm{p}$ and/or $\mathrm{C} 2 \mathrm{p}$ AOs contributed significantly to the MOs of components 2 to 5 . The difference in $E_{\mathrm{B}}$ between the peaks for component $6\left(E_{\mathrm{B}}=14.3 \mathrm{eV}\right)$ and component 1 was $10.6 \mathrm{eV}$; this value matched very well with the $E_{\mathrm{B}}(\mathrm{Cl} 3 \mathrm{~s})$ minus $E_{\mathrm{B}}(\mathrm{Cl} 3 \mathrm{p})$ value of $\sim 11 \mathrm{eV}$ for a $\mathrm{NaCl}$ single crystal. ${ }^{67}$ In addition, the area of component 6 at $E_{\mathrm{B}}=14.3 \mathrm{eV}$ decreased (relative to component 1 for $\mathrm{Cl} 3 p$ ) with decreasing $h v$ (Figure $2 b$ ); component 6 was also more intense than the other peaks in the $E_{\mathrm{B}}<12 \mathrm{eV}$ region, especially at $h v=1486.6 \mathrm{eV}$. At $h v=1486.6 \mathrm{eV}$ the $\mathrm{Cl} 3$ s photoionisation cross section is larger than the $\mathrm{Cl} 3 p$ photoionisation cross section, whereas as at $h v=198.0 \mathrm{eV}$ the $\mathrm{Cl} 3 p$ photoionisation cross section is larger than the $\mathrm{Cl} 3 \mathrm{~s}$ photoionisation cross section (ESI Section 6). Furthermore, at $h v=1486.6 \mathrm{eV}$ the $\mathrm{Cl} 3 \mathrm{~s}$ photoionisation cross section is larger than the $\mathrm{N} 2 \mathrm{p}$ and $\mathrm{C}$ $2 p$ photoionisation cross-sections. These observations demonstrate that the MOs that gave rise to component 6 had significant contributions from $\mathrm{Cl} 3 \mathrm{~s}$ AOs. 


\subsection{RAES}

In ESI Section 16 a brief description is given of the $E_{\mathrm{B}}$ values at which peaks due to participator Auger and spectator Auger transitions appear. Peaks due to participator Auger transitions can be identified with high confidence at $E_{\mathrm{B}}<10 \mathrm{eV}$. At $E_{\mathrm{B}}>10 \mathrm{eV}$, peaks due to spectator Auger transitions may have contributed to the overall RAES signal, although at $10 \mathrm{eV}<E_{\mathrm{B}}<16 \mathrm{eV}$ transitions due to participator Auger transitions are considered far more likely than transitions due to spectator Auger (ESI Section 16). These values are used as a conservative guide for identification of peaks due to participator Auger transitions in our results.

All peaks in the N 1s NEXAFS spectra for the seven ILs for which RAES has been measured here have been identified previously, using a combination of core level XPS, NEXAFS spectroscopy and timedependent density functional theory calculations (ESI Section 15 and reference ${ }^{68}$ ). Identification of peaks in the $O 1 \mathrm{~s}$ and $C 1$ s NEXAFS spectra are given in the ESI Section 15. RAES data not given in the main paper is given in ESI Section 16.

\subsubsection{Nitrogen edge RAES: cation}

For $\left[\mathrm{C}_{8} \mathrm{C}_{1} \mathrm{Im}\right] \mathrm{Cl}$, a broad peak due to resonant enhancement was observed at $h v=401.8 \mathrm{eV}$ and $4 \mathrm{eV}<$ $E_{\mathrm{B}}<7 \mathrm{eV}$ (Figure 3a and 3c). We identify this broad peak as arising from two components, labelled as components 2 and 3 (see explanation in ESI Section 26.1). This peak can be positively identified as being from participator Auger transitions involving $\mathrm{MOs}$ that are located with good overlap of the $\mathrm{N}_{\text {cation }} 1 \mathrm{~s}$ core hole. Consequently, MOs in the valence XP spectrum at $4 \mathrm{eV}<E_{\mathrm{B}}<7 \mathrm{eV}$ have significant contributions from the $\mathrm{N}_{\text {cation }}$ in the imidazolium ring. For $\left[\mathrm{C}_{8} \mathrm{C}_{1} \mathrm{Im}\right] \mathrm{Cl}$, no peak due to resonant enhancement was observed at $E_{\mathrm{B}}=3.7 \mathrm{eV}$ (Figure $3 \mathrm{a}$ and $3 \mathrm{c}$ ), strongly suggesting that component 1 for $\left[\mathrm{C}_{8} \mathrm{C}_{1} \mid \mathrm{m}\right] \mathrm{Cl}$ did not contain a significant contribution from $\mathrm{N}_{\text {cation }}$ in the imidazolium ring.
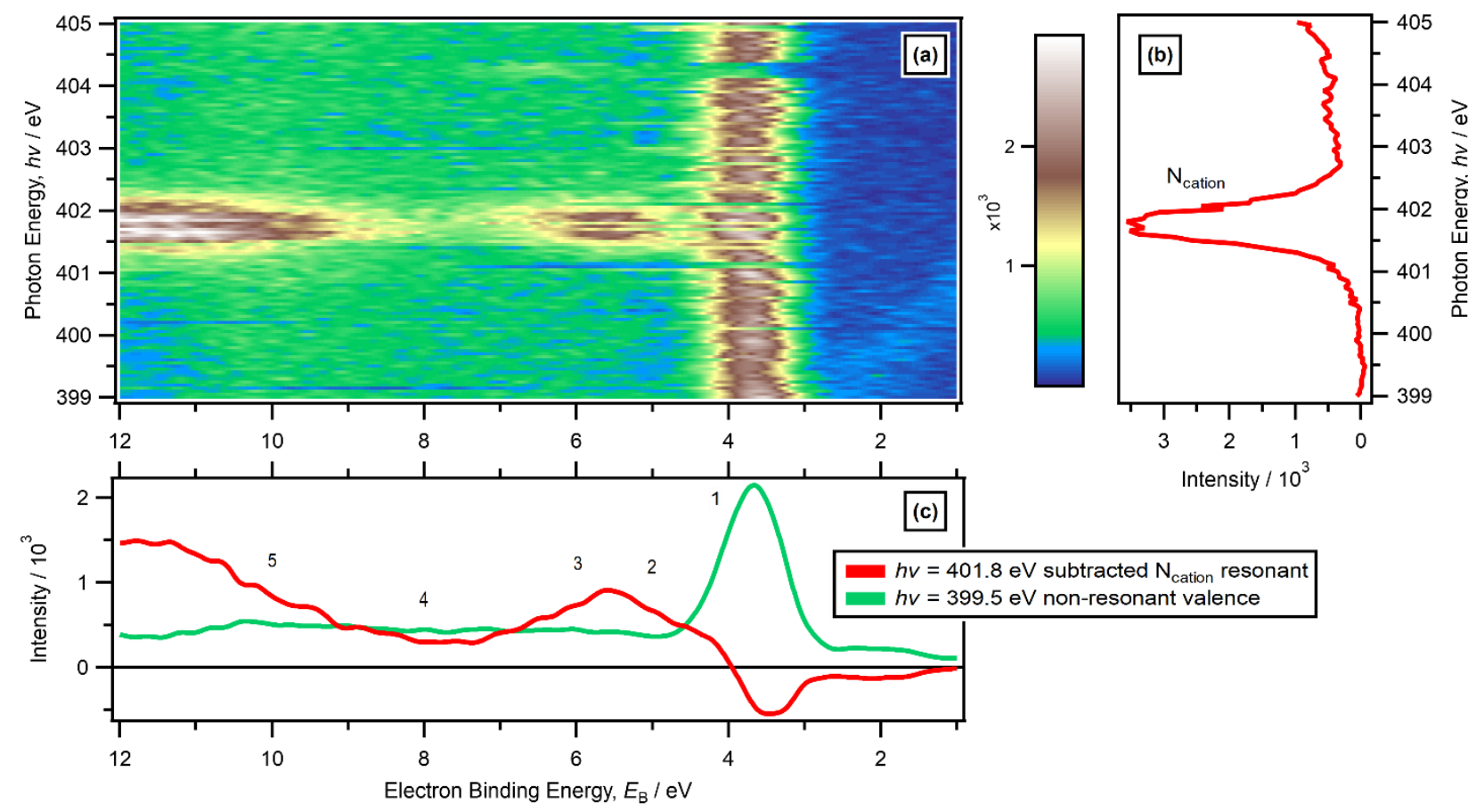

Figure 3. RAES $N$ 1s edge data for $\left[C_{8} C_{1} I m\right] C l$. (a) Heat map of $h v$ against $E_{B}$ for the $N 1$ s edge (produced by combining individual electron spectra taken at varying $h v$ ). (b) Partial electron yield NEXAFS spectrum for the $\mathrm{N} 1 \mathrm{~s}$ edge. (c) Non-resonant valence XP spectrum below the $\mathrm{N} 1 \mathrm{~s}$ absorption edge $(h v=399.5 \mathrm{eV})$ and subtracted $\mathrm{N}_{\text {cation }}$ resonant Auger electron spectrum $(h v=401.8 \mathrm{eV})$. The RAES trace was produced by subtraction of non-resonant XP contributions using the procedure outlined in 
ESI Section 10.3. Component labels 1 to 5 are given in (c). All electron spectra were charge referenced using procedures outlined in ESI Section 5.

For $\left[\mathrm{C}_{4} \mathrm{C}_{1} \mid \mathrm{m}\right][\mathrm{SCN}]$ and $\left[\mathrm{C}_{8} \mathrm{C}_{1} \mid \mathrm{m}\right]\left[\mathrm{C}(\mathrm{CN})_{3}\right]$, the $\mathrm{N}$ 1s NEXAFS spectra were dominated by $\mathrm{N}_{\text {anion }}$ contributions. ${ }^{68}$ However, $\mathrm{N}_{\text {cation }}$ contributions were clearly identifiable at $h v=401.8 \mathrm{eV}$.

For $\left[\mathrm{C}_{4} \mathrm{C}_{1} \mathrm{Im}\right][\mathrm{SCN}]$, areas of components 2 and 3 at $4 \mathrm{eV}<E_{\mathrm{B}}<7 \mathrm{eV}$ were enhanced at the $\mathrm{N}_{\text {cation }} 1 \mathrm{~s}$ edge energy $(h v=401.8 \mathrm{eV})$, relative to below the edge (Figure 4a and $4 \mathrm{c})$. Therefore, MOs which gave rise to components 2 and 3 had significant contributions from $N_{\text {cation }} A O$ s, i.e. the imidazolium ring. The MOs which gave rise to component 1 had no participator Auger contributions from $\mathrm{N}_{\text {cation. }}$.

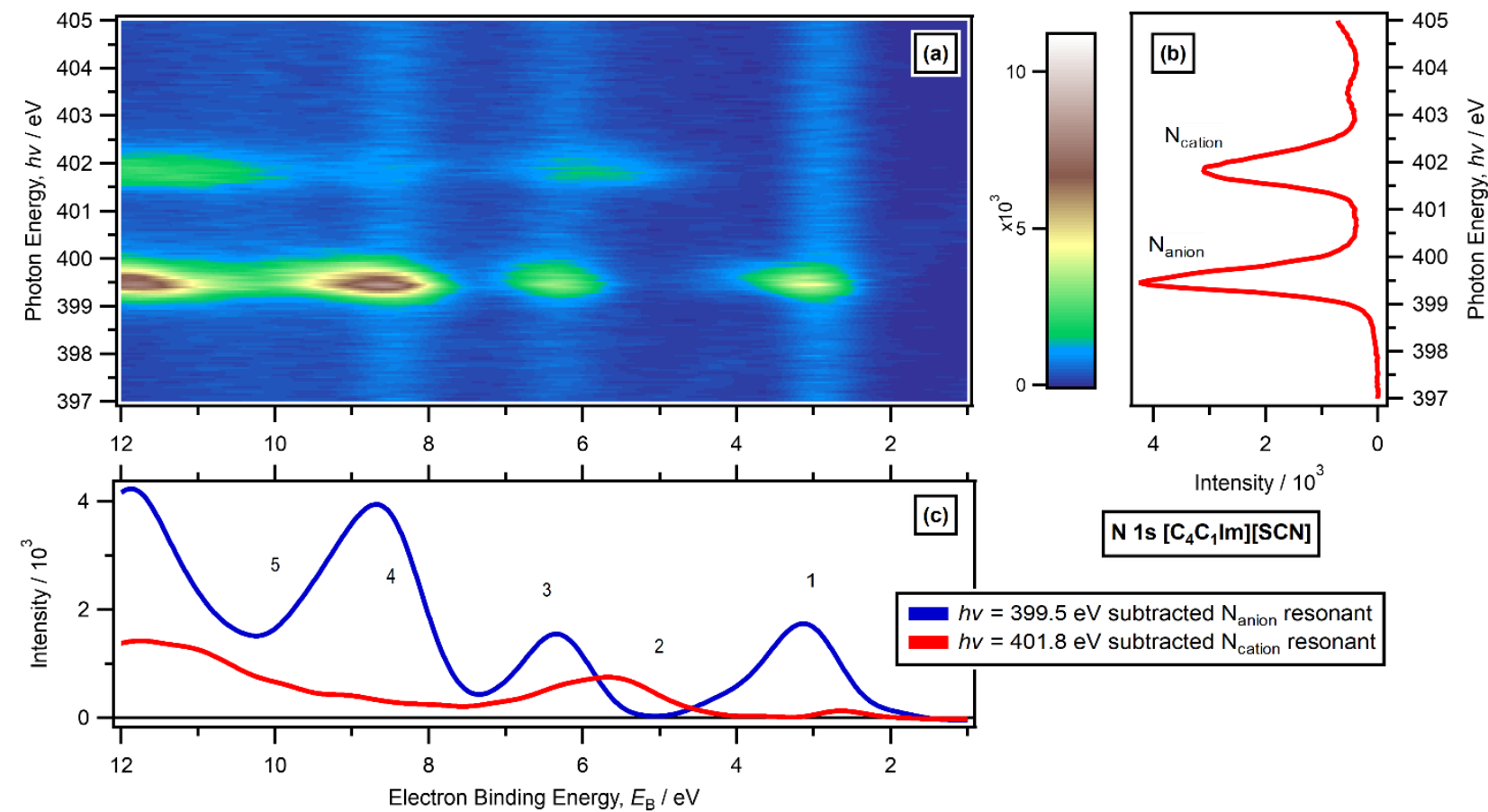

Figure 4. RAES $N$ 1s edge data for $\left[\mathrm{C}_{4} \mathrm{C}_{1} I \mathrm{Im}\right][\mathrm{SCN}]$. (a) Heat map of $h v$ against $E_{\mathrm{B}}$ for the $\mathrm{N} 1 \mathrm{~s}$ edge (produced by combining individual electron spectra taken at varying $h v$ ). (b) Partial electron yield NEXAFS spectrum for the $\mathrm{N} 1 \mathrm{~s}$ edge. (c) Subtracted $\mathrm{N}_{\text {anion }}$ resonant Auger electron spectrum ( $h v=$ $399.5 \mathrm{eV}$ ) and subtracted $\mathrm{N}_{\text {cation }}$ resonant Auger electron spectrum $(h v=401.8 \mathrm{eV})$. The RAES traces were produced by subtraction of non-resonant XP contributions using the procedure outlined in ESI Section 10.3. Component labels 1 to 5 are given in (c). All electron spectra were charge referenced using procedures outlined in ESI Section 5.

For $\left[\mathrm{C}_{8} \mathrm{C}_{1} \mathrm{Im}\right]\left[\mathrm{C}(\mathrm{CN})_{3}\right]$, areas of components 2 and 3 at $4 \mathrm{eV}<E_{\mathrm{B}}<8 \mathrm{eV}$ were also enhanced at the $\mathrm{N}_{\text {cation }}$ 1 s edge energy $(h v=401.8 \mathrm{eV})$, relative to below the edge (Figure $5 \mathrm{a}$ and $5 \mathrm{c})$. Therefore, MOs which gave rise to components 2 and 3 had significant contributions from $\mathrm{N}_{\text {cation }} A O$ s, i.e. the imidazolium ring. The MOs which gave rise to component 1 had no participator Auger contributions from $\mathrm{N}_{\text {cation. }}$. 


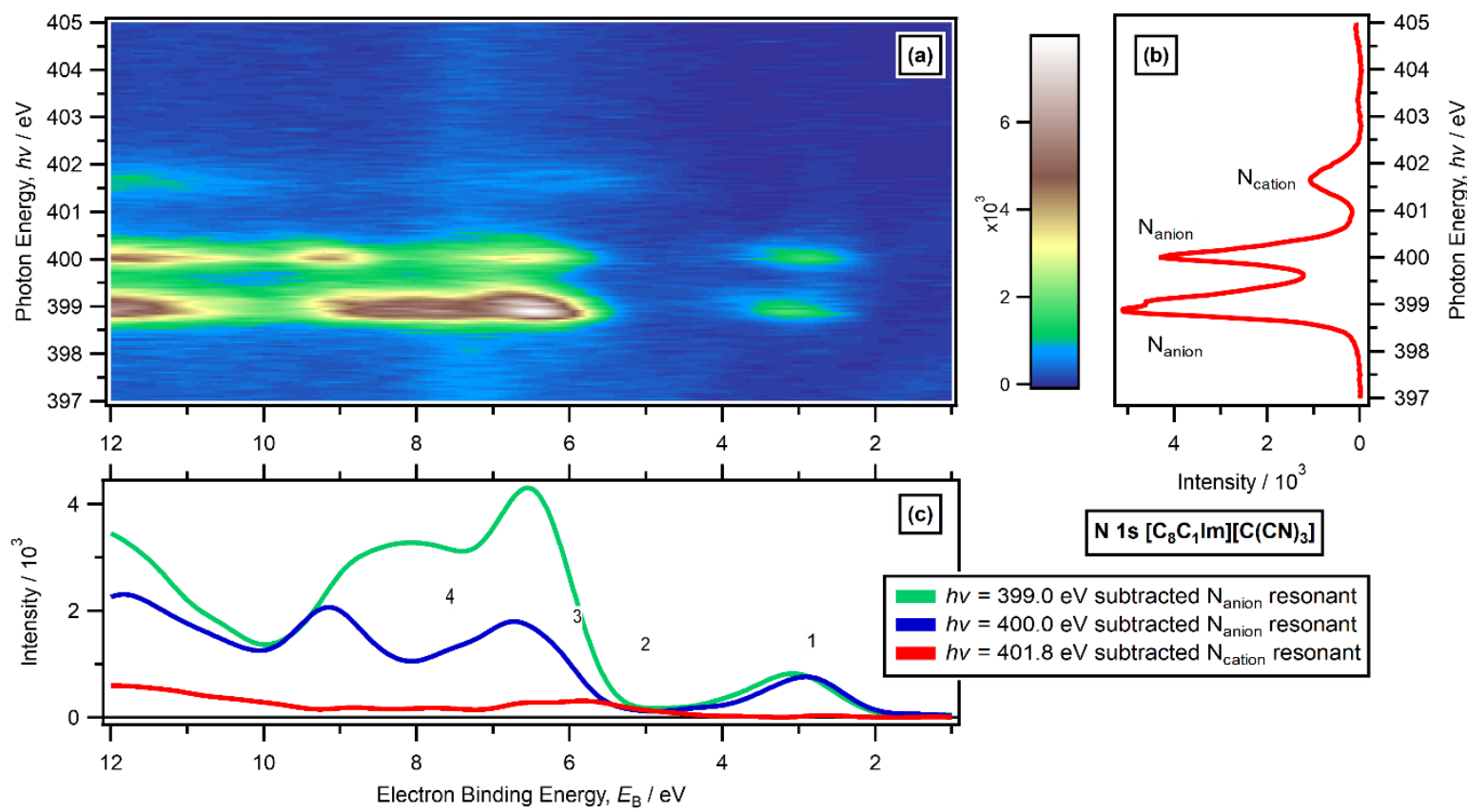

Figure 5. RAES $N$ 1s edge data for $\left[\mathrm{C}_{8} \mathrm{C}_{1} \mathrm{Im}\right]\left[\mathrm{C}(\mathrm{CN})_{3}\right]$. (a) Heat map of $h v$ against $E_{\mathrm{B}}$ for the $\mathrm{N} 1 \mathrm{~s}$ edge (produced by combining individual electron spectra taken at varying $h v$ ). (b) Partial electron yield NEXAFS spectrum for the $\mathrm{N} 1 \mathrm{~s}$ edge. (c) Subtracted $\mathrm{N}_{\text {anion }}$ resonant electron spectra $(h v=399.0 \mathrm{eV}$ and $h v=400.0 \mathrm{eV}$ ), and subtracted $\mathrm{N}_{\text {cation }}$ resonant Auger electron spectrum ( $\left.h v=401.8 \mathrm{eV}\right)$. The RAES traces were produced by subtraction of non-resonant XP contributions using the procedure outlined in ESI Section 10.3. Component labels 1 to 4 are given in (c). All electron spectra were charge referenced using procedures outlined in ESI Section 5.

In summary, for $\left[\mathrm{C}_{8} \mathrm{C}_{1} I \mathrm{~m}\right] \mathrm{Cl},\left[\mathrm{C}_{4} \mathrm{C}_{1} \mathrm{Im}\right][\mathrm{SCN}]$ and $\left[\mathrm{C}_{8} \mathrm{C}_{1} \mathrm{Im}\right]\left[\mathrm{C}(\mathrm{CN})_{3}\right]$ at the $\mathrm{N}_{\text {cation }} 1 \mathrm{~s}$ absorption edge $(h v=$ $401.8 \mathrm{eV}$ ) and at $E_{\mathrm{B}}<12 \mathrm{eV}$, there was a relatively broad feature at $4 \mathrm{eV}<E_{\mathrm{B}}<8 \mathrm{eV}$ (Figures 3, 4, 5 and ESI Figure S74). This feature can be confidently assigned as arising from an $\mathrm{N}_{\text {cation }}$ participator Auger transition. $\left[\mathrm{C}_{8} \mathrm{C}_{1} \mathrm{Im}\right] \mathrm{Cl},\left[\mathrm{C}_{4} \mathrm{C}_{1} \mathrm{Im}\right][\mathrm{SCN}]$ and $\left[\mathrm{C}_{8} \mathrm{C}_{1} \mathrm{Im}\right]\left[\mathrm{C}(\mathrm{CN})_{3}\right]$ all gave similar RAES spectral shapes at $E_{\mathrm{B}}$ $>8 \mathrm{eV}$ (ESI Figure S74), confirming that cationic contributions dominated these traces.

For $\left[\mathrm{C}_{8} \mathrm{C}_{1} \mathrm{Im}\right]\left[\mathrm{NTf} \mathrm{f}_{2}\right]$, the $\mathrm{N}$ 1s RAE spectrum gave an enhancement at $h v=401.8 \mathrm{eV}$ and $4 \mathrm{eV}<E_{\mathrm{B}}<7 \mathrm{eV}$ (ESI Figure S61) due to a participator Auger transition. Leading on from the assignment of this feature at $h v=401.8 \mathrm{eV}$ and $4 \mathrm{eV}<E_{\mathrm{B}}<7 \mathrm{eV}$ for the other three $\left[\mathrm{C}_{n} \mathrm{C}_{1} \mathrm{Im}[\mathrm{A}] \mathrm{ILs}\right.$ studied here as arising from an $\mathrm{N}_{\text {cation }}$ participator Auger transition, for $\left[\mathrm{C}_{8} \mathrm{C}_{1} \mathrm{Im}\right]\left[\mathrm{NTf}_{2}\right]$ this feature at $h v=401.8 \mathrm{eV}$ and $4 \mathrm{eV}<E_{\mathrm{B}}<7$ $\mathrm{eV}$ can confidently be assigned as having a significant contribution from an $\mathrm{N}_{\text {cation }}$ participator Auger transition. Further evidence for this assignment is the excellent visual match of the $\mathrm{N}$ 1s RAE spectra at $h v=401.8 \mathrm{eV}$ and $7 \mathrm{eV}<E_{\mathrm{B}}<12 \mathrm{eV}$ (ESI Figure S74) for the four [ $\mathrm{C}_{n} \mathrm{C}_{1} \mathrm{Im}[\mathrm{A}]$ ILs studied here.

Overall, for all four $\left[\mathrm{C}_{n} \mathrm{C}_{1} \mathrm{Im}[\mathrm{A}]\right.$ ILs studied here using RAES, $\mathrm{N}_{\text {cation }}$ gave a feature in the region of $4 \mathrm{eV}$ $<E_{\mathrm{B}}<7 \mathrm{eV}$ (summarised in Tables 1 and 2 and ESI Table S8 and ESI Table S9). As this feature is in the $p$ region $\left(E_{\mathrm{B}}<12 \mathrm{eV}\right)$, we assign this feature as arising from $N 2 \mathrm{p}$ AOs.

No clear peaks due to participator Auger transitions were observed for the $\mathrm{N} 1 \mathrm{~s}$ edge for the two ammonium-based ILs (ESI Figure S62 and ESI Figure S63); an explanation for this observation is given in ESI Section 17. Therefore, MOs with significant contribution from the cationic AOs could not be identified using $\mathrm{N}$ 1s RAES for these two ILs. 


\subsubsection{Nitrogen edge RAES: anion}

For $\left[\mathrm{C}_{4} \mathrm{C}_{1} \mathrm{Im}\right][\mathrm{SCN}]$, areas of components 1,3 and 4 were enhanced at the anionic $\mathrm{N}$ 1s edge energy ( $h \mathrm{v}$ $=399.5 \mathrm{eV}$ ), relative to below the edge, due to participator Auger transitions (Figure 4a and 4c). Therefore, the RAES data suggests that for $\left[\mathrm{C}_{4} \mathrm{C}_{1} \mathrm{Im}\right][\mathrm{SCN}]$ components 1,3 and 4 have significant contributions from anionic nitrogen. Furthermore, the N 1s RAES data suggests that component 2 has no significant anionic nitrogen contributions, as no enhancement in component area was observed at the anionic $\mathrm{N}$ 1s edge energy.

For $\left[\mathrm{C}_{8} \mathrm{C}_{1} \mathrm{Im}\right]\left[\mathrm{C}(\mathrm{CN})_{3}\right]$, the anion gave two well-resolved resonant peaks in the $\mathrm{N} 1 \mathrm{~s}$ NEXAFS spectrum, at $h v=399.0 \mathrm{eV}$ and $h v=400.1 \mathrm{eV}$ (Figure 5b). ${ }^{68}$ Areas of components 1 (at $E_{\mathrm{B}} \sim 2.8 \mathrm{eV}$ ), 2, 3 and 4 were enhanced at the anionic $\mathrm{N} 1 \mathrm{~s}$ resonant energies ( $h v=399.0 \mathrm{eV}$ and $h v=400.1 \mathrm{eV}$ ), relative to below the edge, due to participator Auger transitions (Figure $5 a$ and $5 c$ ). Therefore, the RAES data suggests that for $\left[\mathrm{C}_{8} \mathrm{C}_{1} \mathrm{Im}\right]\left[\mathrm{C}(\mathrm{CN})_{3}\right]$ components $1,2,3$ and 4 have significant contributions from anionic nitrogen.

For $\left.\left[\mathrm{P}_{6,6,6,14]}\right] \mathrm{NO}_{3}\right]$, resonant enhancement was observed at the anionic $\mathrm{N}$ 1s edge energy $(h v=405.1$ $\mathrm{eV}^{68}$ and $E_{\mathrm{B}}=\sim 10 \mathrm{eV}$ ), relative to below the edge (ESI Figure S64). This peak is identified with reasonable confidence as being from a participator Auger transition. No peaks due to participator Auger transitions were observed at $E_{\mathrm{B}}<10 \mathrm{eV}$ for $\left[\mathrm{P}_{6,6,6,14}\right]\left[\mathrm{NO}_{3}\right]$, strongly indicating that the $\mathrm{MOs}$ nearest to $E_{\mathrm{F}}$ have little or no contribution from anionic $N$ AOs. Similar conclusions were made for $\mathrm{N}$ 1s RAES data for $\mathrm{Na}\left[\mathrm{NO}_{3}\right]$ (ESI Section 18). ${ }^{42}$

For $\left[\mathrm{C}_{n} \mathrm{C}_{1} \mathrm{Im}\right]\left[\mathrm{NTf} f_{2}\right]$, no clear peak arising from the $\left[\mathrm{NTf}_{2}\right]^{-}$anion can be identified in the $\mathrm{N}$ 1s NEXAFS spectrum (ESI Figure $\mathrm{S} 61 \mathrm{~b}$ and reference ${ }^{68}$ ). For $\left[\mathrm{C}_{n} \mathrm{C}_{1} \mathrm{Im}\right]\left[\mathrm{NTf}_{2}\right]$, experiments and calculations (both transition potential DFT and time-dependent DFT) suggest that the lowest energy peak due to the $\left[\mathrm{NTf}_{2}\right]^{-}$anion in the $\mathrm{N}$ 1s NEXAFS spectrum would appear at a similar energy to the lowest energy peak for the imidazolium ring. ${ }^{68-71}$ Therefore, the feature at $h v=401.8 \mathrm{eV}$ and $4 \mathrm{eV}<E_{\mathrm{B}}<7 \mathrm{eV}$ for $\left[\mathrm{C}_{8} \mathrm{C}_{1} \mathrm{Im}\right]\left[\mathrm{NTf}_{2}\right]$ (ESI Figure S61) could potentially be due to either a cationic participator Auger transition or an anionic participator Auger transition. However, given the excellent visual match of the $\mathrm{N}$ 1s RAE spectrum at $h v=401.8 \mathrm{eV}$ and $0 \mathrm{eV}<E_{\mathrm{B}}<12 \mathrm{eV}$ for the four $\left[\mathrm{C}_{n} \mathrm{C}_{1} \mathrm{Im}\right][\mathrm{A}]$ ILs studied here (ESI Figure S74), the feature at $h v=401.8 \mathrm{eV}$ and $4 \mathrm{eV}<E_{\mathrm{B}}<7 \mathrm{eV}$ for $\left[\mathrm{C}_{8} \mathrm{C}_{1} \mathrm{Im}\right]\left[\mathrm{NTf}_{2}\right]$ was confidently assigned as arising mainly from $\mathrm{N}_{\text {cation }}$ and not $\mathrm{N}_{\text {anion. }}$.

\subsubsection{Oxygen edge RAES: anion}

For $\left[\mathrm{N}_{2,2,1,0}\right][\mathrm{TfO}]$, the area of component $1\left(E_{\mathrm{B}} \sim 6 \mathrm{eV}\right)$ was enhanced at the anionic $\mathrm{O}$ 1s edge energy $(h v \sim 535 \mathrm{eV})$, relative to below the edge, due to participator Auger transitions (Figure 6a and 6c). Therefore, the RAES data suggests that for $\left[\mathrm{N}_{2,2,1,0}\right][\mathrm{TfO}]$ component 1 has significant contributions from anionic oxygen. The area of component $2\left(E_{\mathrm{B}} \sim 10 \mathrm{eV}\right)$ gave relatively small area enhancements at the anionic $O 1 \mathrm{~s}$ edge energy, (Figure $6 \mathrm{a}$ and $6 \mathrm{c}$ ), suggesting that component 2 has only small contributions from anionic oxygen. The features at $E_{\mathrm{B}}>\sim 12 \mathrm{eV}$ are likely due to either spectator Auger or a combination of both spectator Auger and participator Auger transitions (i.e. not solely due to participator Auger transitions); therefore, no attempts have been made to draw conclusions on valence MOs at $E_{\mathrm{B}}>12 \mathrm{eV}$ for the $\mathrm{O} 1 \mathrm{~s}$ RAES spectra of $\left[\mathrm{N}_{2,2,1,0}\right][\mathrm{TfO}]$. 


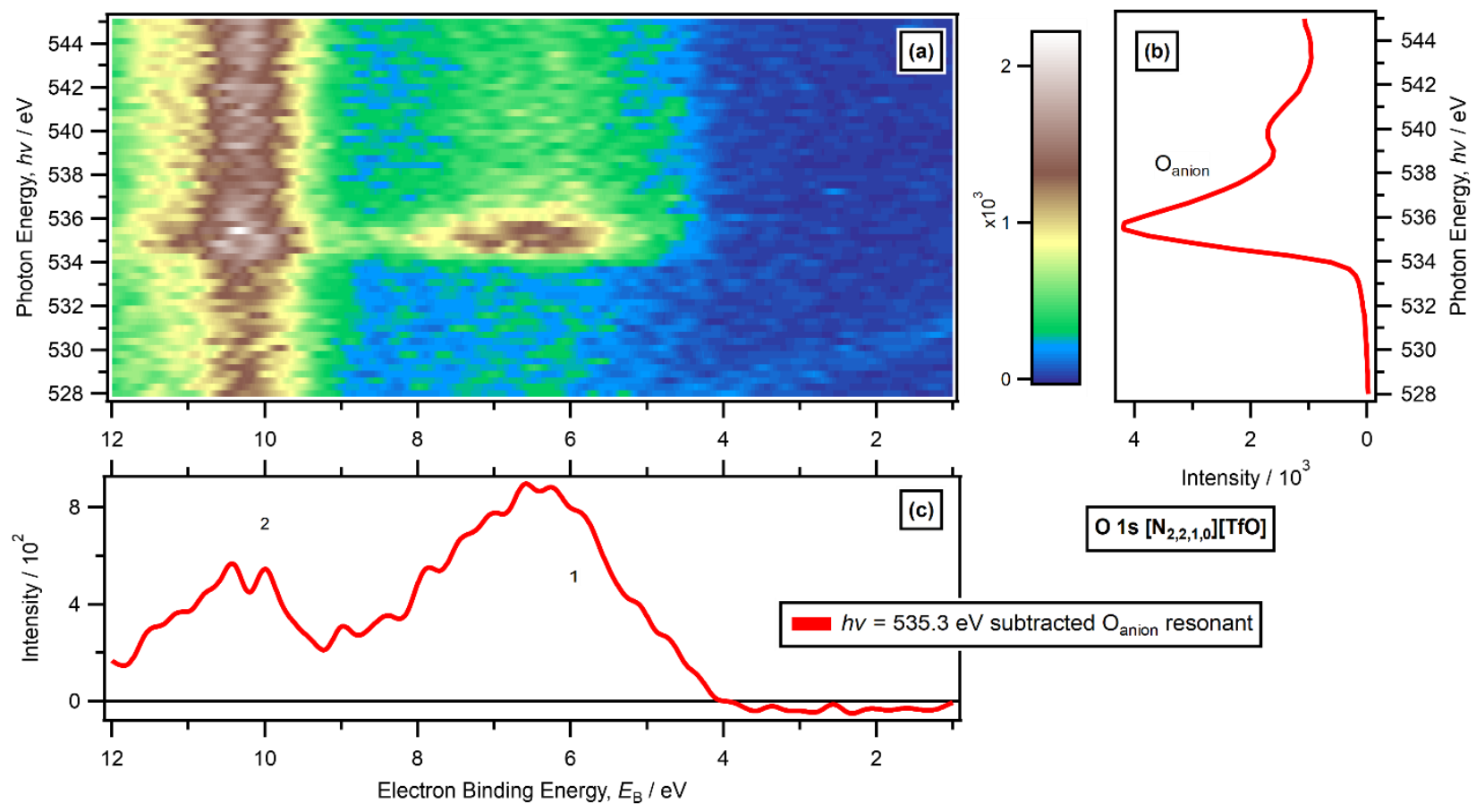

Figure 6. RAES $O 1 \mathrm{~s}$ edge data for $\left[\mathrm{N}_{2,2,1,0}\right][\mathrm{TfO}]$. (a) Heat map of $h v$ against $E_{\mathrm{B}}$ for the $O 1 \mathrm{~s}$ edge (produced by combining individual electron spectra taken at varying $h v$ ). (b) Partial electron yield NEXAFS spectrum for the $O 1$ s edge. (c) Subtracted $O_{\text {anion }}$ resonant Auger electron spectrum $(h v=$ $535.3 \mathrm{eV}$ ). The RAES trace was produced by subtraction of non-resonant XP contributions using the procedure outlined in ESI Section 10.3. Component labels 1 and 2 are given in (c). All electron spectra were charge referenced using procedures outlined in ESI Section 5.

For $\left[\mathrm{C}_{8} \mathrm{C}_{1} \mathrm{Im}\right]\left[\mathrm{NTf}_{2}\right],\left[\mathrm{P}_{6,6,6,14}\right]\left[\mathrm{NO}_{3}\right]$ and $\left[\mathrm{N}_{4,1,1,0}\right]\left[\mathrm{HSO}_{4}\right]$ identification of anionic oxygen contributions to the valence electronic structure were made by observation of peaks due to participator Auger transitions; these identifications are summarised in the ESI Section 17. For all three ILs, anionic oxygen contributed significantly to component 1.

\subsubsection{Carbon edge RAES: cation and anion}

For $\left[\mathrm{C}_{8} \mathrm{C}_{1} \mathrm{Im}\right]\left[\mathrm{NTf}_{2}\right]$, the areas of components 1 and 2 were enhanced due to peaks from participator Auger transitions at the $\mathrm{C} 1 \mathrm{~s}$ edge energies $(h v=286.6 \mathrm{eV}$ and $287.2 \mathrm{eV})$ relative to below the edge (Figure 7). These peaks at $h v \sim 287 \mathrm{eV}$ corresponded to absorption by the imidazolium ring $\mathrm{C}_{\text {cation }}$ (see ESI Section 15 for more details). Therefore, MOs which gave rise to components 1 and 2 had significant contributions from $\mathrm{C} 2 \mathrm{p}$ AOs of the imidazolium ring.

For $\left[\mathrm{P}_{6,6,6,14]}\right]\left[\mathrm{NO}_{3}\right]$, a low intensity and broad peak was observed due to participator Auger transitions at $5 \mathrm{eV}<E_{\mathrm{B}}<11 \mathrm{eV}$ at the $\mathrm{C}$ 1s edge energy ( $h v \sim 288 \mathrm{eV}$, ESI Figure S72), labelled as components 2, 3 and 4. Therefore, MOs which gave rise to components 2, 3 and 4 had significant contributions from $\mathrm{C}_{\text {cation }} 2 \mathrm{p}$ AOs. Furthermore, no peak due to participator Auger transitions was observed for component 1 , strongly suggesting that there was no significant cationic $\mathrm{C} 2 \mathrm{p}$ AO contribution to components 1 .

For $\left[\mathrm{N}_{4,1,1,0}\right]\left[\mathrm{HSO}_{4}\right]$ a very low intensity, broad peak was observed due to participator Auger transitions at $6 \mathrm{eV}<E_{\mathrm{B}}<12 \mathrm{eV}$ and $h v \sim 288.5 \mathrm{eV}$ (ESI Figure S70). This corresponds to components 2, 3 and 4 having significant contributions from $\mathrm{C}_{\text {cation }} 2 \mathrm{p}$ AOs for $\left[\mathrm{N}_{4,1,1,0}\right]\left[\mathrm{HSO}_{4}\right]$. 


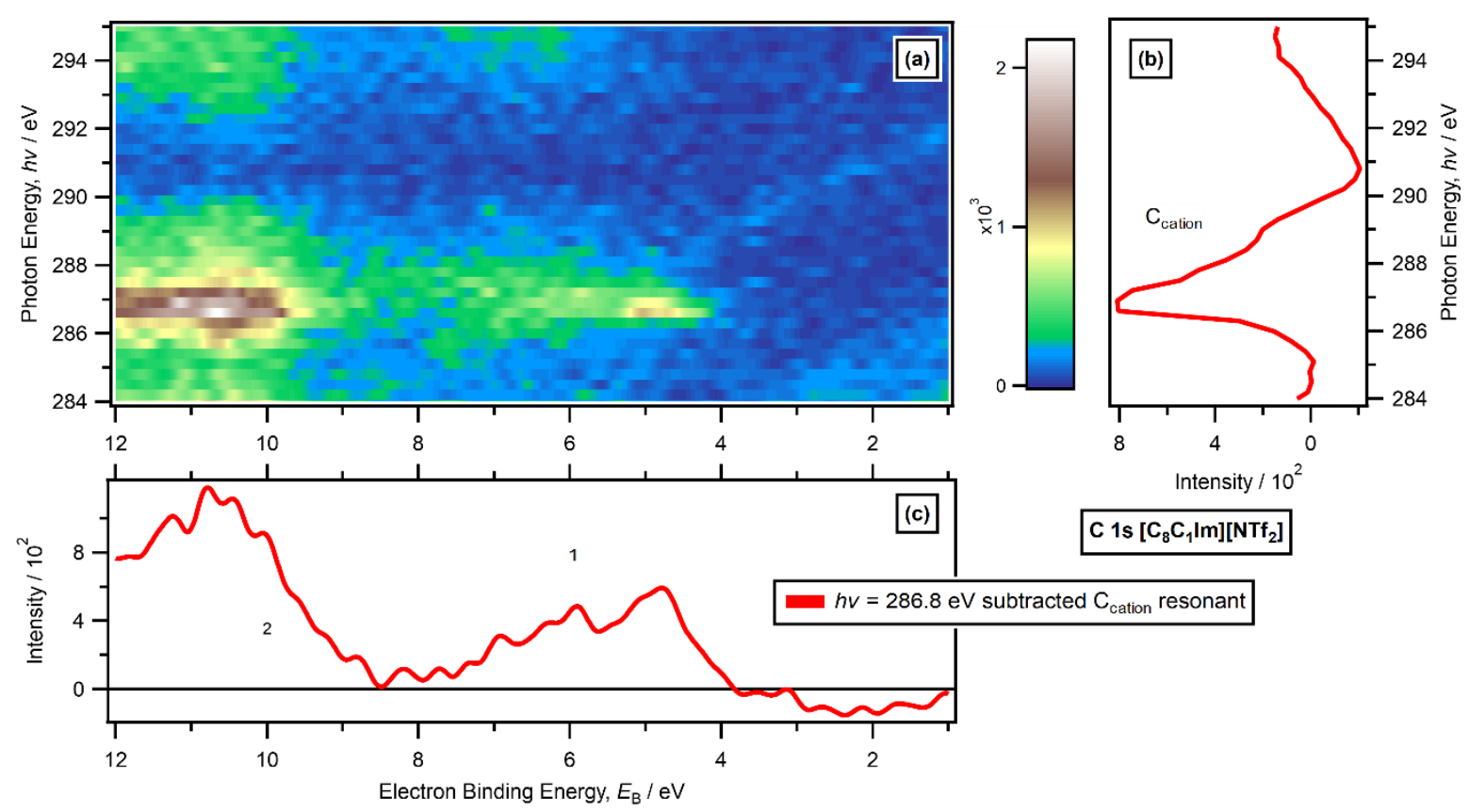

Figure 7. RAES $C$ 1s edge data for $\left[\mathrm{C}_{8} \mathrm{C}_{1} \mathrm{Im}\right]\left[\mathrm{NTf}_{2}\right]$. (a) Heat map of $h v$ against $E_{\mathrm{B}}$ for the $\mathrm{C} 1 \mathrm{~s}$ edge (produced by combining individual electron spectra taken at varying $h v$ ). (b) Partial electron yield NEXAFS spectrum for the $C 1$ s edge. (c) Subtracted $C_{\text {cation }}$ resonant Auger electron spectrum $(h v=$ $286.8 \mathrm{eV}$ ). The RAES trace was produced by subtraction of non-resonant XP contributions using the procedure outlined in ESI Section 10.3. Component labels 1 and 2 are given in (c). All electron spectra were charge referenced using procedures outlined in ESI Section 5. 


\subsection{Fingerprint method}

The fingerprint method is a simpler data analysis method than the subtraction method that will be introduced in Section 3.4. In addition, valence XP spectrum can be compared that are recorded under different conditions, e.g. on different apparatus or with different analyser settings. Using peak identification from other experimental methods, e.g. from RAES, can also help MO identification using the fingerprint method.

\subsubsection{Fingerprint method: halide anion ILs}

For $\left[\mathrm{C}_{8} \mathrm{C}_{1} \mathrm{Im}\right] \mathrm{Cl}$, peaks due to $\mathrm{Cl}^{-}$-based MOs were identified in Section 3.1 at $E_{\mathrm{B}}=3.7 \mathrm{eV}$ and $E_{\mathrm{B}}=14.3$ $\mathrm{eV}$ (Table 2). For $\left[\mathrm{P}_{6,6,6,14}\right] \mathrm{Cl}$ the valence XP spectrum at $h v=1486.6 \mathrm{eV}$ gave relatively intense, approximately Gaussian-shaped peaks at $E_{\mathrm{B}}=3.1 \mathrm{eV}$ and $E_{\mathrm{B}} \sim 13.9 \mathrm{eV}$ compared to the other peaks in the XP spectrum (ESI Figure S76b). The peak $E_{B}$ separation for $\left[\mathrm{P}_{6,6,6,14}\right] \mathrm{Cl}, 10.8 \mathrm{eV}$, matched that observed for $\mathrm{Cl}^{-}$in $\left[\mathrm{C}_{8} \mathrm{C}_{1} \mathrm{~lm}\right] \mathrm{Cl}$ (Table 2) and $\mathrm{NaCl}^{67}$ Also, all four peaks identified as being from $\mathrm{Cl}^{-}$gave relatively intense, sharp valence peaks. At $h v=1486.6 \mathrm{eV}$ the $\mathrm{Cl} 3 p$ photoionisation cross-section is $\sim 90$ times larger than $\mathrm{C} 2 \mathrm{p}$ and $\sim 20$ times larger than $\mathrm{N} 2 p,{ }^{37}$ explaining the observation of relatively intense peaks due to $\mathrm{Cl} 3 p$ relative to $\mathrm{N} 2 p$ and $\mathrm{C} 2 p$ (the $\mathrm{Cl} 3 p$ photoionisation cross-section is $\sim 4$ times larger than $\mathrm{C} 2 \mathrm{~s}$ and $\sim 2$ times larger than $\left.\mathrm{N} 2 \mathrm{~s},{ }^{37}\right)$. Therefore, two peaks for $\left[\mathrm{P}_{6,6,6,14}\right] \mathrm{Cl}$ can be positively identified as being from $\mathrm{Cl}^{-}$-based MOs. The valence $X P$ spectra for $\left[\mathrm{C}_{8} \mathrm{C}_{1} \mathrm{Im}\right] \mathrm{Br}$ gave peaks at $E_{\mathrm{B}}=3.2$ $\mathrm{eV}$ and $E_{\mathrm{B}}=13.8 \mathrm{eV}$ (ESI Figure $\mathrm{S} 76 \mathrm{c}$ ), and for $\left[\mathrm{P}_{6,6,6,14}\right] \mathrm{Br}$ gave peaks at $E_{\mathrm{B}}=2.9 \mathrm{eV}$ and $E_{\mathrm{B}}=13.7$ (ESI Figure $\mathrm{S} 76 \mathrm{~d})$ ). Peaks due to $\mathrm{Br}^{-}$can be readily identified at $E_{\mathrm{B}} \sim 3 \mathrm{eV}(\mathrm{Br} 4 \mathrm{p})$ and $E_{\mathrm{B}} \sim 14 \mathrm{eV}(\mathrm{Br} 4 \mathrm{~s})$. The valence XP spectrum for $\left[\mathrm{C}_{6} \mathrm{C}_{1} \mathrm{Im}\right] \mathrm{l}$ gave two peaks at $1.4 \mathrm{eV}<E_{\mathrm{B}}<4.5 \mathrm{eV}$ (ESI Figure S76e). For $\left[\mathrm{C}_{6} \mathrm{C}_{1} \mathrm{Im}\right] \mathrm{I}$, these peaks can be identified as originating from I $5 p$-based MOs). The spin-orbit splitting was also readily observed, showing both $I 5 p_{3 / 2}$ and $I 5 p_{1 / 2}$ peaks. The peak separation $\left[C_{6} C_{1} I m\right] I$ was $0.93 \mathrm{eV}$, exactly matching that found for $\mathrm{I}^{-}$dissolved in water ${ }^{25}$. These observations contribute to the positive identification of the $15 p$ contributions.

\subsubsection{Obtaining an individual ion trace for the $\left[\mathrm{C}_{8} \mathrm{C}_{1} \mathrm{Im}\right]^{+}$cation}

The area normalisation method used in this paper is a very reliable and reproducible method (ESI Section 11). Therefore, this method can be used to obtain individual ion traces, most importantly for the $\left[\mathrm{C}_{8} \mathrm{C}_{1} \mathrm{Im}\right]^{+}$cation (ESI Section 9). For $\left[\mathrm{C}_{8} \mathrm{C}_{1} \mathrm{Im}\right] \mathrm{Cl}$, all peaks apart from the intense, relatively Gaussian-shaped peaks at $E_{\mathrm{B}}=3.7 \mathrm{eV}$ and $E_{\mathrm{B}}=14.3 \mathrm{eV}$ were due to the $\left[\mathrm{C}_{8} \mathrm{C}_{1} \mathrm{Im}\right]^{+}$cation (Section 3.1); therefore, for $\left[C_{8} C_{1} I m\right] C l$ all features in the region $5.5 \mathrm{eV}<E_{B}<11.5 \mathrm{eV}$ were from the $\left[\mathrm{C}_{8} \mathrm{C}_{1} \mathrm{Im}\right]^{+}$cation. For $\left[\mathrm{C}_{8} \mathrm{C}_{1} \mathrm{Im}\right]\left[\mathrm{BF}_{4}\right]$, all features in the region $0 \mathrm{eV}<E_{\mathrm{B}}<6.5 \mathrm{eV}$ were from the $\left[\mathrm{C}_{8} \mathrm{C}_{1} 1 \mathrm{~m}\right]^{+}$cation (ESI Figure S77b and S77c). By splicing together sections of the area normalised valence XP spectra for $\left[\mathrm{C}_{8} \mathrm{C}_{1} \mathrm{Im}\right]\left[\mathrm{BF}_{4}\right]\left(0 \mathrm{eV}<E_{\mathrm{B}}<5.95 \mathrm{eV}\right)$ and $\left[\mathrm{C}_{8} \mathrm{C}_{1} \mathrm{Im}\right] \mathrm{Cl}\left(5.96 \mathrm{eV}<E_{\mathrm{B}}<11.5 \mathrm{eV}\right)$ an area normalised trace for $\left[\mathrm{C}_{8} \mathrm{C}_{1} \mathrm{Im}\right]^{+}$was obtained for $0 \mathrm{eV}<E_{\mathrm{B}}<11.5 \mathrm{eV}$ (Figure 8). Given the relatively small contribution from alkyl carbon-based C $2 p$ AOs to the region at $0 \mathrm{eV}<E_{\mathrm{B}}<11.5 \mathrm{eV}$, this trace for $\left[\mathrm{C}_{8} \mathrm{C}_{1} \mathrm{Im}\right]^{+}$can be used as the trace for $\left[C_{n} C_{1} I m\right]^{+}$(where $\left.n=2,4,6\right)$. 


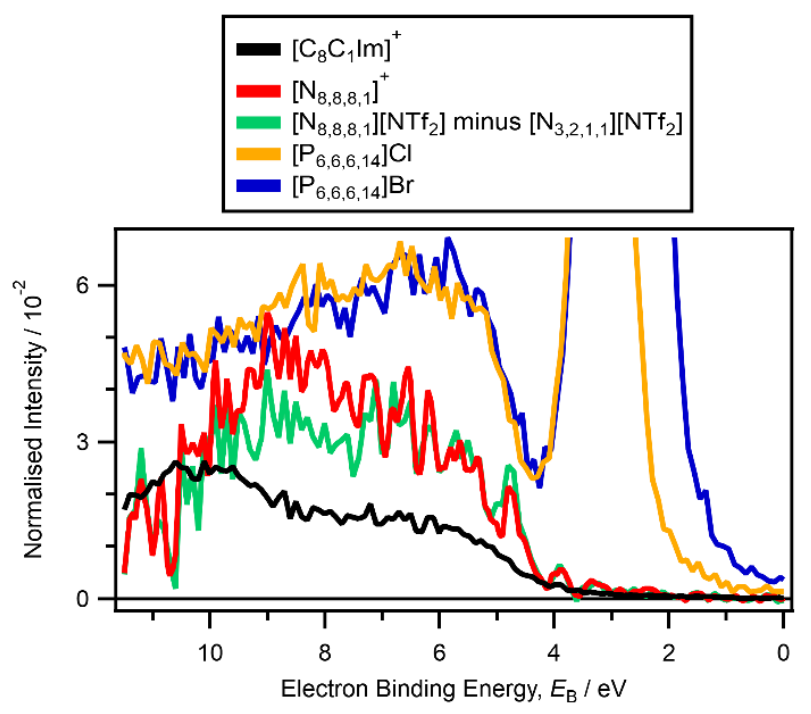

Figure 8. Cation traces for $\left[\mathrm{C}_{8} \mathrm{C}_{1} \mathrm{Im}\right]^{+}$and $\left[\mathrm{N}_{8,8,8,1}\right]^{+}$. Area normalised valence XP spectrum recorded at $h v=1486.6 \mathrm{eV}$ for $\left[\mathrm{P}_{6,6,6,6,14}\right] \mathrm{Cl}$ and $\left[\mathrm{P}_{6,6,6,14}\right] \mathrm{Br}$. The areas were normalised using procedures outlined in ESI Section 8.2. Subtraction was performed using procedures outlined in ESI Section 10.1. The cation traces were obtained using procedures outlined in ESI Section 9. All electron spectra were charge referenced using procedures outlined in ESI Section 5.

\subsubsection{Fingerprint method for $\left[C_{n} C_{1} I m\right]^{+}:$RAES traces versus individual ion trace}

For all four of the $\left[C_{n} C_{1} I m\right][A]$ ILs studied here using RAES (see Section 3.2.1), the $N_{\text {cation }} 1 \mathrm{~s} \rightarrow \pi^{*}$ resonance gave a feature in the region of $4 \mathrm{eV}<E_{\mathrm{B}}<7 \mathrm{eV}$ (summarised in Tables 1 and 2 and ESI Table S8 and ESI Table S9). A comparison, area normalised by eye, of the $\mathrm{N}_{\text {cation }}$ RAES traces for the four ILS versus the cation trace for $\left[\mathrm{C}_{8} \mathrm{C}_{1} \mathrm{Im}\right]^{+}$for data recorded at $h v=1486.6 \mathrm{eV}$ showed an excellent match for the feature at $4 \mathrm{eV}<E_{\mathrm{B}}<6 \mathrm{eV}$ (Figure 9). A comparison, area normalised by eye, of the $\mathrm{C}_{\text {cation }} \mathrm{RAES}$ traces for $\left[\mathrm{C}_{8} \mathrm{C}_{1} \mathrm{Im}\right]\left[\mathrm{NTf}_{2}\right]$ versus the cation trace for $\left[\mathrm{C}_{8} \mathrm{C}_{1} \mathrm{Im}\right]^{+}$for data recorded at $h v=1486.6 \mathrm{eV}$ showed an excellent match for the feature at $4 \mathrm{eV}<E_{\mathrm{B}}<6 \mathrm{eV}$ (ESI Figure S77a). Furthermore, a comparison, area normalised by eye, of the $\mathrm{N}_{\text {cation }}$ RAES traces for the four ILs versus area normalised valence XP spectra for $\left[\mathrm{C}_{8} \mathrm{C}_{1} \mathrm{Im}\right]\left[\mathrm{BF}_{4}\right],\left[\mathrm{C}_{6} \mathrm{C}_{1} \mathrm{Im}\right]\left[\mathrm{B}(\mathrm{CN})_{4}\right]$ and $\left[\mathrm{C}_{8} \mathrm{C}_{1} \mathrm{Im}\right]\left[\mathrm{C}(\mathrm{CN})_{3}\right]$ (recorded at $h v=1486.6$ $\mathrm{eV}$ ) showed an excellent match for the feature at $4 \mathrm{eV}<E_{\mathrm{B}}<6 \mathrm{eV}$ (ESI Figure S77b). Lastly, a comparison (again normalised by eye) of the valence XP spectrum recorded at $h v=198.0 \mathrm{eV}$ for $\left[\mathrm{C}_{8} \mathrm{C}_{1} \mathrm{Im}\right] \mathrm{Cl}$ and the valence XP spectrum recorded at $h v=1486.6 \mathrm{eV}$ for $\left[\mathrm{C}_{8} \mathrm{C}_{1} \mathrm{Im}\right]\left[\mathrm{BF}_{4}\right]$ both showed the same feature at $4.5 \mathrm{eV}<E_{\mathrm{B}}<6 \mathrm{eV}$ (ESI Figure $\mathrm{S77}$ ). 


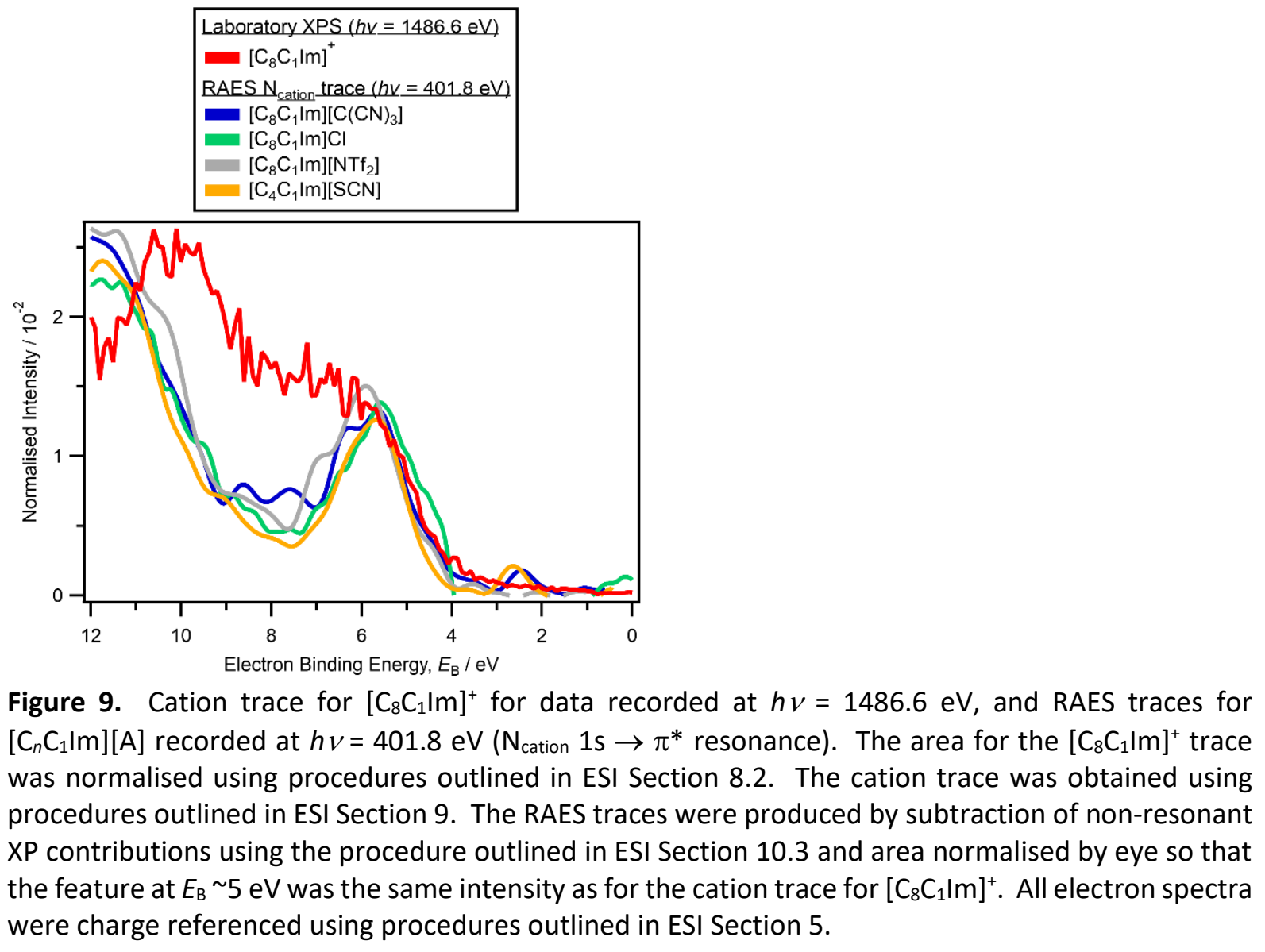




\subsection{Subtraction method for valence level XP spectra}

Much data is available for laboratory-based XP spectrometers recorded using $h v=1486.6 \mathrm{eV}$. For such data, area subtraction can be attempted (see ESI Section 8 for an explanation of how the areas were normalised). For example, the $\left[C_{n} C_{1} I m\right]^{+}$trace can be used for subtraction in combination with area normalised valence XP spectra for $\left[C_{n} C_{1} I m\right][A]$ ILs to obtain traces for $[A]$. Using these traces for $[\mathrm{A}]^{-}$, further cation traces can be obtained. In addition, for certain ILs it was possible to identify $\left[\mathrm{C}_{n} \mathrm{C}_{1} \mathrm{Im}\right]^{+}$contributions when the subtraction of an area normalised valence XP spectrum for $\left[C_{n} C_{1} I m\right][A]$ minus the $\left[C_{n} C_{1} \mid m\right]^{+}$trace gave a trace that matched closely to the zero line.

\subsubsection{Subtraction method: identifying cationic and anionic alkyl contributions}

The subtracted trace for $\left[\mathrm{N}_{8,8,8,1}\right]\left[\mathrm{NTf}_{2}\right]$ minus $\left[\mathrm{N}_{3,2,1,1}\right]\left[\mathrm{NTf}_{2}\right]$ (ILs with the same cation core but very different alkyl chain lengths) showed a positive deviation from the zero line in the $\mathrm{p} A O$ region at $E_{\mathrm{B}}<$ $11.5 \mathrm{eV}$ (Figure 8). No clear peaks were observed, suggesting that the relatively large number of $\left[\mathrm{N}_{8,8,8,1}\right]^{+}$cationic MOs gave a range of $E_{\mathrm{B}}$ values. Furthermore, a visual inspection of the subtracted trace and the $\left[\mathrm{N}_{8,8,8,1}\right]\left[\mathrm{NTf}_{2}\right]$ valence XP spectrum showed that the onset energies were relatively similar (Figure 8).

For ILs with a difference of $\mathrm{C}_{4} \mathrm{H}_{8}$ alkyl units, e.g. $\left[\mathrm{C}_{8} \mathrm{C}_{1} \mathrm{Im}\right]\left[\mathrm{HSO}_{4}\right]$ minus $\left[\mathrm{C}_{4} \mathrm{C}_{1} \mathrm{Im}\right]\left[\mathrm{HSO}_{4}\right]$ or $\left[\mathrm{N}_{8,1,1,0}\right]\left[\mathrm{HSO}_{4}\right]$ minus $\left[\mathrm{N}_{4,1,1,0}\right]\left[\mathrm{HSO}_{4}\right]$, little positive deviation from the zero line was observed in the subtracted trace in the $\mathrm{p} \mathrm{AO}$ region at $E_{\mathrm{B}}<12 \mathrm{eV}$ (ESI Figure S81). Furthermore, for ILs with the same anion core and relatively different alkyl chain lengths, $\left[\mathrm{C}_{4} \mathrm{C}_{1} \mathrm{Im}\right]\left[\mathrm{OcSO}_{4}\right]$ minus $\left[\mathrm{C}_{4} \mathrm{C}_{1} \mathrm{Im}\right]\left[\mathrm{MeSO}_{4}\right]$ (ESI Figure S82a), little deviation from the zero line was observed in the $\mathrm{p} A \mathrm{O}$ region of the subtracted traces. For ILs with the same cation core and very similar alkyl chain lengths, essentially no deviation from the zero line was observed in the subtracted traces, e.g. for $\left[\mathrm{N}_{4,1,1,1}\right]\left[\mathrm{NTf}_{2}\right]$ minus $\left[\mathrm{N}_{3,2,1,1}\right]\left[\mathrm{NTf}_{2}\right],\left[\mathrm{S}_{2,2,2}\right]\left[\mathrm{NTf}_{2}\right]$ minus $\left[\mathrm{S}_{2,2,1}\right]\left[\mathrm{NTf} f_{2}\right]$, and $\left[\mathrm{C}_{4} \mathrm{C}_{0} \mathrm{Im}\right]\left[\mathrm{NTf}_{2}\right]$ minus $\left[\mathrm{C}_{2} \mathrm{C}_{0} \mathrm{Im}\right]\left[\mathrm{NTf} \mathrm{f}_{2}\right]$ (ESI Figure S80a, ESI Figure S80d and ESI Figure $\mathrm{S} 80 \mathrm{c}$ respectively), as expected.

For IL XP spectra recorded at $h v=1486.6 \mathrm{eV}$, the subtraction method only worked well when considering ILs with large differences in the number of alkyl carbons. The $C 2 p$ photoionisation crosssection is small at $h v=1486.6 \mathrm{eV}$, relative to AOs such as $\mathrm{F} 2 \mathrm{p}$ and S $3 p .{ }^{37}$ Therefore, changing the alkyl chain length in an IL generally had minimal effect on the valence XP spectra. The subtraction method would work better for XP spectra recorded at $h v$ significantly lower than $h v=1486.6 \mathrm{eV}$, as the $C 2 p$ photoionisation cross-section increases at lower $h v$, relative to AOs such as $F 2 p$ and S $3 p .{ }^{37}$ These observations (and those previously highlighted in Section 3.1 and Section 3.2.4) demonstrate the challenge identifying $C_{\text {alkyl }}$ contributions to the valence $p$ AO region of ILs.

A major advantage of the minimal impact of alkyl chains on the $\mathrm{p} \mathrm{AO}$ region for data recorded at $h v=$ $1486.6 \mathrm{eV}$ is that the subtraction method can be used for data recorded at $h v=1486.6 \mathrm{eV}$ where the ILs have similar, but not the same, alkyl chains in their structure. For example, $\left[\mathrm{S}_{2,2,2}\right]\left[\mathrm{NTf}_{2}\right]$ and $\left[\mathrm{N}_{3,2,1,1}\right]\left[\mathrm{NTf}_{2}\right]$ can be compared using the subtraction method, even though they have slightly different alkyl chains in the IL.

\subsubsection{Subtraction method: identifying cationic non-alkyl contributions}

For $\left[\mathrm{C}_{8} \mathrm{C}_{1} \mathrm{Im}\right]\left[\mathrm{C}(\mathrm{CN})_{3}\right]$, the peak at $E_{\mathrm{B}}=2.8 \mathrm{eV}$ has already been identified using RAES as originating from the $\left[\mathrm{C}(\mathrm{CN})_{3}\right]^{-}$anion (Section 3.2). The next feature was at $4 \mathrm{eV}<E_{\mathrm{B}}<6 \mathrm{eV}$, with a more intense feature at $6 \mathrm{eV}<E_{\mathrm{B}}<9 \mathrm{eV}$ (Figure 10a). The feature at $4 \mathrm{eV}<E_{\mathrm{B}}<6 \mathrm{eV}$ matched the $E_{\mathrm{B}}$ range for the feature identified using $N_{\text {cation }} 1 \mathrm{~s}$ RAES data for the four $\left[C_{n} C_{1} I m\right][A]$ ILs (Section 3.2.1). Furthermore, the subtracted anion trace $\left(\left[\mathrm{C}_{8} \mathrm{C}_{1} \mathrm{Im}\right]\left[\mathrm{C}(\mathrm{CN})_{3}\right]\right.$ minus the $\left[\mathrm{C}_{8} \mathrm{C}_{1} \mathrm{Im}\right]^{+}$trace) showed a very close match to the 
zero line at $3.5 \mathrm{eV}<E_{\mathrm{B}}<5.5 \mathrm{eV}$ (Figure 10a). Therefore, the feature at $4 \mathrm{eV}<E_{\mathrm{B}}<6 \mathrm{eV}$ can be identified as arising from the $\left[\mathrm{C}_{8} \mathrm{C}_{1} / \mathrm{m}\right]^{+}$cation.
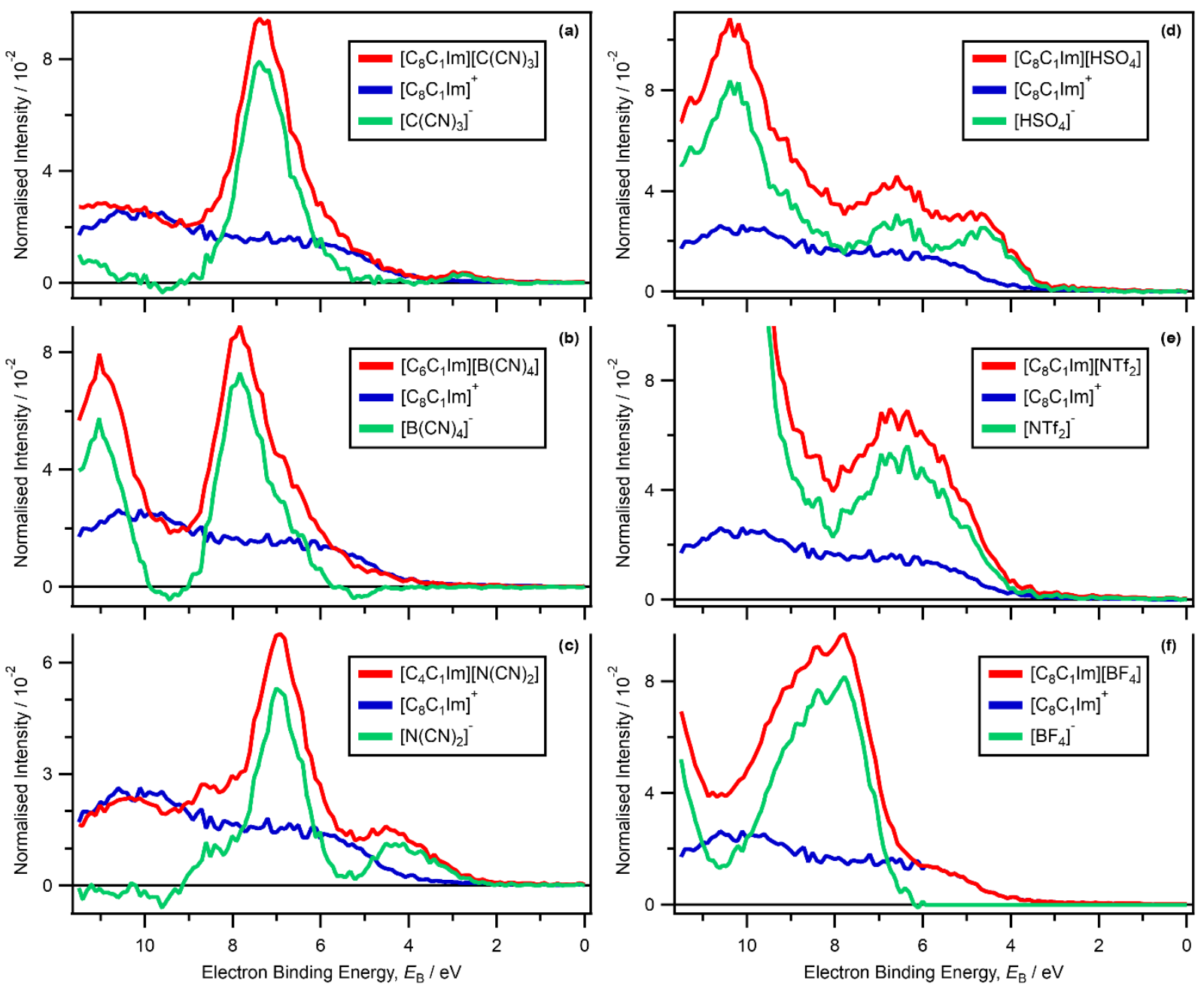

Figure 10. Area normalised valence XP spectrum recorded at $h v=1486.6 \mathrm{eV}$, spliced $\left[\mathrm{C}_{8} \mathrm{C}_{1} \mathrm{Im}\right]^{+}$trace and subtracted anion trace for: (a) $\left[\mathrm{C}_{8} \mathrm{C}_{1} \mathrm{Im}\right]\left[\mathrm{C}(\mathrm{CN})_{3}\right]$, (b) $\left[\mathrm{C}_{6} \mathrm{C}_{1} \mathrm{Im}\right]\left[\mathrm{B}(\mathrm{CN})_{4}\right]$, (c) $\left[\mathrm{C}_{4} \mathrm{C}_{1} \mathrm{Im}\right]\left[\mathrm{N}(\mathrm{CN})_{2}\right]$, (d) $\left[\mathrm{C}_{8} \mathrm{C}_{1} \mathrm{Im}\right]\left[\mathrm{HSO}_{4}\right]$, (e) $\left[\mathrm{C}_{8} \mathrm{C}_{1} \mathrm{Im}\right]\left[\mathrm{NTf}_{2}\right]$, (f) $\left[\mathrm{C}_{8} \mathrm{C}_{1} \mathrm{Im}\right]\left[\mathrm{BF}_{4}\right]$. The areas were normalised using procedures outlined in ESI Section 8.2. Subtraction was performed using procedures outlined in ESI Section 10.1. The spliced $\left[\mathrm{C}_{8} \mathrm{C}_{1} \mathrm{Im}\right]^{+}$trace and the subtracted anion traces were obtained using procedures outlined in ESI Section 9. All electron spectra were charge referenced using procedures outlined in ESI Section 5.

For $\left[\mathrm{C}_{6} \mathrm{C}_{1} \mathrm{Im}\right]\left[\mathrm{B}(\mathrm{CN})_{4}\right]$, the lowest $E_{\mathrm{B}}$ feature was at $4 \mathrm{eV}<E_{\mathrm{B}}<6 \mathrm{eV}$, followed by a more intense feature at $6 \mathrm{eV}<E_{\mathrm{B}}<9 \mathrm{eV}$ (Figure 10b and ESI Figure S87d). Again, this feature matched the $E_{\mathrm{B}}$ range for the feature identified using $\mathrm{N}_{\text {cation }}$ 1s RAES data for the four $\left[\mathrm{C}_{n} \mathrm{C}_{1} \mathrm{Im}\right][\mathrm{A}]$ ILs (Section 3.2.1 and ESI Figure S77b). Furthermore, the subtracted anion trace $\left(\left[\mathrm{C}_{6} \mathrm{C}_{1} \mathrm{Im}\right]\left[\mathrm{B}(\mathrm{CN})_{4}\right]\right.$ minus the $\left[\mathrm{C}_{8} \mathrm{C}_{1} \mathrm{Im}\right]^{+}$trace) showed a close match to the zero line at $0 \mathrm{eV}<E_{\mathrm{B}}<5.5 \mathrm{eV}$ (Figure 10b). Therefore, the feature at $4 \mathrm{eV}<E_{\mathrm{B}}<$ $6 \mathrm{eV}$ can be identified as arising from the $\left[\mathrm{C}_{6} \mathrm{C}_{1} \mathrm{Im}\right]^{+}$cation. Furthermore, for $\left[\mathrm{C}_{4} \mathrm{C}_{1} \mathrm{Im}\right]\left[\mathrm{N}(\mathrm{CN})_{2}\right]$ and $\left[\mathrm{C}_{4} \mathrm{C}_{1} \mid \mathrm{m}\right][\mathrm{SCN}]$, the subtracted anion traces both closely matched to the zero line at $4.5 \mathrm{eV}<E_{\mathrm{B}}<5.5$ $\mathrm{eV}$ (Figure $10 \mathrm{c}$ and ESI Figure S87a), indicating a contribution arising from the $\left[\mathrm{C}_{4} \mathrm{C}_{1} \mathrm{Im}\right]^{+}$cation for this $E_{\mathrm{B}}$ region.

$\left[\mathrm{C}_{n} \mathrm{C}_{1} \mathrm{Im}\right]^{+}$contributions to the region $5 \mathrm{eV}<E_{\mathrm{B}}<11.5 \mathrm{eV}$ were identified, including identification (for ILs with a range of structurally different anions) of a feature due to $\left[\mathrm{C}_{n} \mathrm{C}_{1} \mathrm{Im}\right]^{+}$at $9 \mathrm{eV}<E_{\mathrm{B}}<11.5 \mathrm{eV}$ (ESI 
Section 22). Furthermore, the minimal impact on valence electronic structure of ILs with protic cations (compared to ILs with aprotic cations) is also demonstrated (ESI Section 22).

For $\left[P_{6,6,6,14}\right] \mathrm{Cl}$ and $\left[\mathrm{P}_{6,6,6,14}\right] \mathrm{Br}$ peaks due to the anion have already been identified using the fingerprint method (Section 3.3). Given the small number of contributions from the halide anions, all peaks/features in the valence XP spectra for $\left[\mathrm{P}_{6,6,6,14}\right] \mathrm{Cl}$ and $\left[\mathrm{P}_{6,6,6,14}\right] \mathrm{Br}$ at $h v=1486.6 \mathrm{eV}$, other than those due to the halide anions, can be readily identified as emanating from the $\left[\mathrm{P}_{6,6,6,14}\right]^{+}$cation. The subtracted trace for $\left[\mathrm{P}_{6,6,6,14}\right] \mathrm{Br}$ minus $\left[\mathrm{P}_{6,6,6,14}\right] \mathrm{Cl}$ matched to the zero line almost perfectly at $4.5 \mathrm{eV}<$ $E_{\mathrm{B}}<11.5 \mathrm{eV}$; signals due to the halide anions were at $1.5 \mathrm{eV}<E_{\mathrm{B}}<4 \mathrm{eV}$ and $12 \mathrm{eV}<E_{\mathrm{B}}<14.5 \mathrm{eV}$ (ESI Figure $\mathrm{S} 91 \mathrm{~b}$ ). This $4.5 \mathrm{eV}<E_{\mathrm{B}}<11.5 \mathrm{eV}$ range matched almost perfectly to the $\mathrm{C} 1 \mathrm{~s}$ RAES identification for $\left[\mathrm{P}_{6,6,6,14}\right]\left[\mathrm{NO}_{3}\right]$ cationic MOs at $5 \mathrm{eV}<E_{\mathrm{B}}<11 \mathrm{eV}$ (Section 3.2.4). Therefore, this feature at $4.5 \mathrm{eV}<$ $E_{\mathrm{B}}<11.5 \mathrm{eV}$ can be confidently identified as emanating from $\left[\mathrm{P}_{6,6,6,14}\right]^{+}$cation $\mathrm{C} 2 \mathrm{p}$-based MOs.

The $\left[\mathrm{N}_{8,8,8,1}\right]^{+}$cation trace matched closely to the $\left[\mathrm{N}_{8,8,8,1}\right]\left[\mathrm{NTf}_{2}\right]$ minus $\left[\mathrm{N}_{3,2,1,1}\right]\left[\mathrm{NTf} f_{2}\right]$ trace (Figure 8). In addition, the onset $E_{B}$ for the $\left[\mathrm{N}_{8,8,8,1}\right]^{+}$cation trace, the $\left[\mathrm{N}_{8,8,8,1}\right]\left[\mathrm{NTf}_{2}\right]$ minus $\left[\mathrm{N}_{3,2,1,1}\right]\left[\mathrm{NTf}_{2}\right]$ trace and the cation contribution for $\left[\mathrm{P}_{6,6,6,14}\right] \mathrm{Cl}$ and $\left[\mathrm{P}_{6,6,6,14}\right] \mathrm{Br}$ all showed a good match. These observations highlight the relative dominance of the alkyl chains for the $\left[\mathrm{N}_{8,8,8,1}\right]^{+}$cation, and no contribution from the $\mathrm{N}$ atom could be identified. For other alkylammonium-based ILs, the $\left[\mathrm{N}_{3,2,1,1}\right]^{+}$and $\left[\mathrm{N}_{3,2,1,1}\right]^{+}$cation traces were close to the zero line. The cation traces for $\left[\mathrm{N}_{2,2,1,0}\right]^{+},\left[\mathrm{N}_{4,1,1,0}\right]^{+}$and $\left[\mathrm{N}_{8,1,1,0}\right]^{+}$all showed small positive deviations from the zero line. Therefore, no conclusions will be drawn on these five cation traces.

The cations in $\left[\mathrm{S}_{2,2,2}\right]\left[\mathrm{NTf}_{2}\right]$ and $\left[\mathrm{N}_{3,2,1,1}\right]\left[\mathrm{NTf} f_{2}\right]$ are structurally different. The $\left[\mathrm{N}_{3,2,1,1}\right]^{+}$cation contains only $\mathrm{C}, \mathrm{N}$ and $\mathrm{H}$ atoms, whereas the $\left[\mathrm{S}_{2,2,2}\right]^{+}$cation contains a $\mathrm{S}$ atom. The subtracted trace for $\left[\mathrm{S}_{2,2,2}\right]\left[\mathrm{NTf}_{2}\right]$ minus $\left[\mathrm{N}_{3,2,1,1}\right]\left[\mathrm{NTf}_{2}\right]$ showed a significant feature in the $\mathrm{p} \mathrm{AO}$ region $\left(0 \mathrm{eV}<E_{\mathrm{B}}<12 \mathrm{eV}\right)$ at $E_{\mathrm{B}} \sim 6 \mathrm{eV}$ (Figure 11a). In addition, three other combinations of similar ILs $\left(\left[\mathrm{S}_{2,2,1}\right]\left[\mathrm{NTf}_{2}\right]\right.$ minus $\left[\mathrm{N}_{3,2,1,1}\right]\left[\mathrm{NTf} f_{2}\right],\left[\mathrm{S}_{2,2,1}\right]\left[\mathrm{NTf} f_{2}\right]$ minus $\left[\mathrm{N}_{4,1,1,1}\right]\left[\mathrm{NTf} f_{2}\right]$, and $\left[\mathrm{S}_{2,2,2}\right]\left[\mathrm{NTf}_{2}\right]$ minus $\left.\left[\mathrm{N}_{4,1,1,1}\right]\left[\mathrm{NTf} \mathrm{f}_{2}\right]\right)$ showed a peak at $E_{\mathrm{B}} \sim 6 \mathrm{eV}$ (ESI Figure 92b). Furthermore, the $\left[\mathrm{S}_{2,2,2}\right]^{+}$and $\left[\mathrm{S}_{2,2,1}\right]^{+}$cation traces both showed a feature at $E_{\mathrm{B}} \sim 6 \mathrm{eV}$ (Figure $11 \mathrm{~b}$ and ESI Figure $83 \mathrm{f}$ respectively). At $h v=1486.6 \mathrm{eV}$, the photoionisation crosssection for $S 3 p$ is $\sim 50$ times greater than that for $C 2 p$ and $\sim 12$ times greater than that for $N 2 p$ (ESI Section 6). ${ }^{37}$ Furthermore, the alkyl carbon contributions to the $\mathrm{p} \mathrm{AO}$ region for the subtracted trace (at $h v=1486.6 \mathrm{eV}$ ) for two ILs which contain similar amounts of alkyl carbon were essentially the same (see Section 3.4.1 and ESI Section 21). Therefore, this peak at $E_{\mathrm{B}} \sim 6 \mathrm{eV}$ is confidently assigned to contributions from the $S 3 p A O$ of the $\left[S_{2,2,2}\right]^{+}$cation. Furthermore, a feature at $9 \mathrm{eV}<E_{B}<12 \mathrm{eV}$ was present for the four different subtracted traces (ESI Figure 92b); this feature can also be assigned to contributions from the $S 3 p A O$ of the $\left[S_{2,2,2}\right]^{+}$cation, although this assignment was with less confidence than for the peak at $E_{\mathrm{B}} \sim 6 \mathrm{eV}$ (as explained in ESI Section 10.2). The subtracted $\left[\mathrm{S}_{2,2,2}\right]\left[\mathrm{NTf}_{2}\right]$ minus $\left[\mathrm{N}_{3,2,1,1}\right]\left[\mathrm{NTf}_{2}\right]$ trace in Figure 11a can be thought of as a representation of the $\mathrm{S} 3 \mathrm{p}$ contributions to the $\left[\mathrm{S}_{2,2,2}\right]\left[\mathrm{NTf}_{2}\right]$ valence electronic structure.

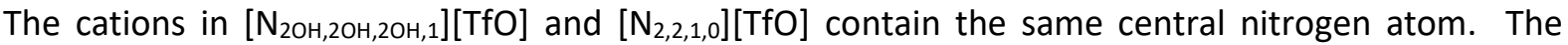

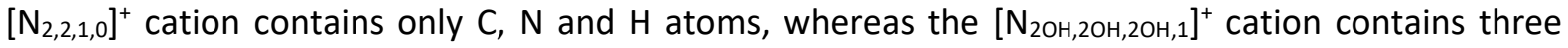

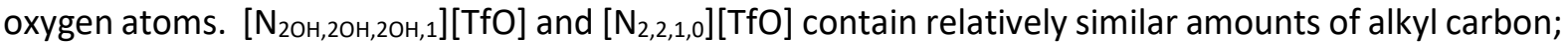
hence these differences should be negligible in the $\mathrm{p} A O$ region. The subtracted trace for

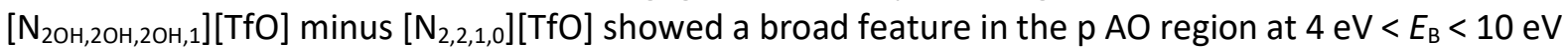

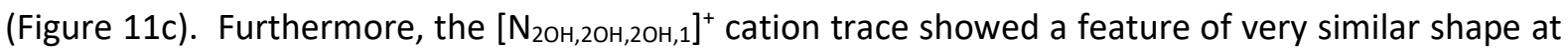
$4 \mathrm{eV}<E_{\mathrm{B}}<10 \mathrm{eV}$ (Figure 11d). At $h v=1486.6 \mathrm{eV}$, the photoionisation cross-section for $\mathrm{O} 2 \mathrm{p}$ is $\sim 12$ times greater than that for $C 2 p$ and $\sim 3$ times greater than that for $N 2 p$ (ESI Section 6 ). ${ }^{37}$ The contribution at $4 \mathrm{eV}<E_{\mathrm{B}}<8 \mathrm{eV}$ can confidently be assigned to contributions from the $\mathrm{O} 2 \mathrm{p} \mathrm{AO}$ of the

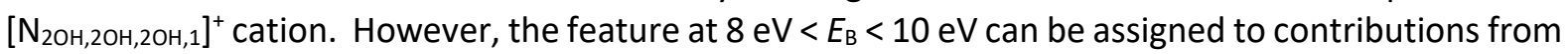

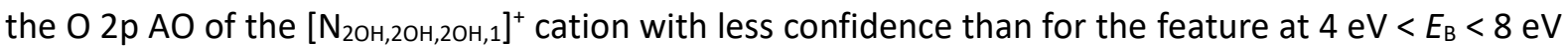


(as explained in ESI Section 10.2). The subtracted trace in Figure 11c can be thought of as a

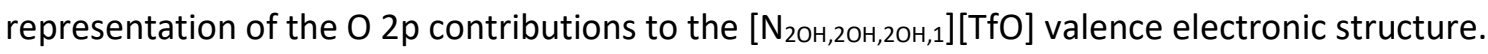
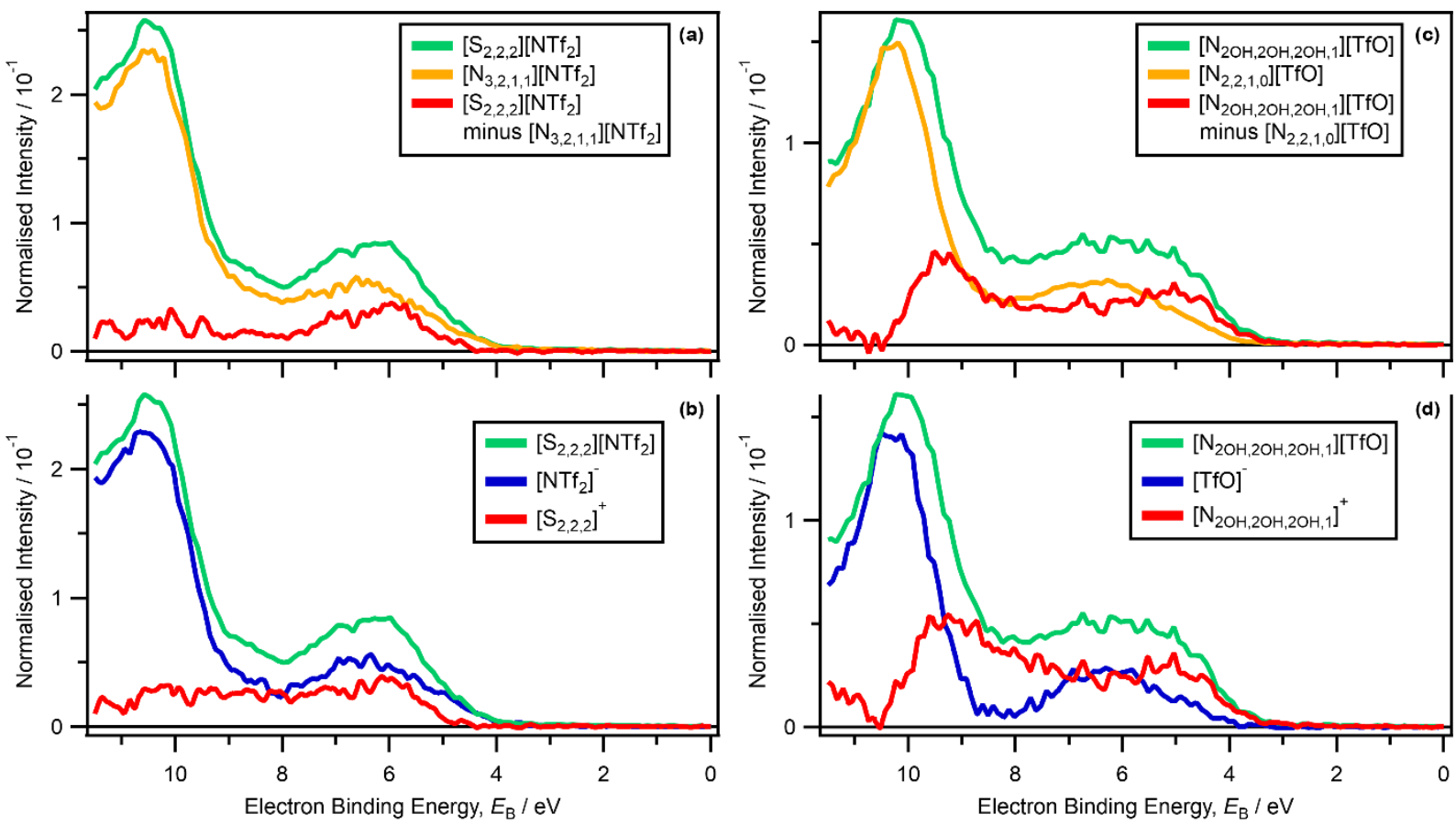

Figure 11. (a) Area normalised valence XP spectra for $\left[\mathrm{S}_{2,2,2}\right]\left[\mathrm{NTf}_{2}\right]$ and $\left[\mathrm{N}_{3,2,1,1}\right]\left[\mathrm{NTf}_{2}\right]$ recorded at $h v=$ $1486.6 \mathrm{eV}$, and the subtracted $\left[\mathrm{S}_{2,2,2}\right]\left[\mathrm{NTf}_{2}\right]$ minus $\left[\mathrm{N}_{3,2,1,1}\right]\left[\mathrm{NTf}_{2}\right]$ trace. (b) Area normalised valence XP spectrum for $\left[\mathrm{S}_{2,2,2}\right]\left[\mathrm{NTf}_{2}\right],\left[\mathrm{NTf}_{2}\right]^{-}$anion trace and $\left[\mathrm{S}_{2,2,2}\right]^{+}$cation trace. (c) Area normalised valence XP

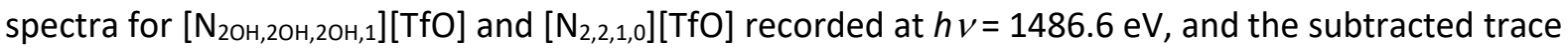

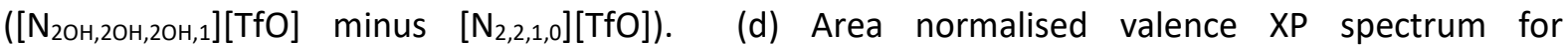

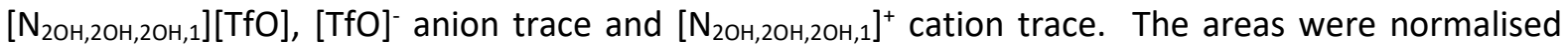
using procedures outlined in ESI Section 8.2; subtraction was performed using procedures outlined in ESI Section 10.1. All electron spectra were charge referenced using procedures outlined in ESI Section 5.

\subsubsection{Subtraction method: identifying anionic non-alkyl contributions}

Identification of anionic contributions for select ILs is presented here. Identification of anionic nonalkyl contributions in the region $5 \mathrm{eV}<E_{\mathrm{B}}<12 \mathrm{eV}$ for other ILs ([SCN], $\left[\mathrm{N}(\mathrm{CN})_{2}\right]^{-},\left[\mathrm{C}(\mathrm{CN})_{3}\right]^{-},\left[\mathrm{B}(\mathrm{CN})_{4}\right]^{-}$, $\left[\mathrm{TfO}^{-},\left[\mathrm{NTf}_{2}\right]^{-},\left[\mathrm{HSO}_{4}\right]^{-},\left[\mathrm{MeSO}_{4}\right]^{-},\left[\mathrm{OCSO}_{4}\right]^{-},\left[\mathrm{MeSO}_{3}\right]^{-},\left[\mathrm{Me}_{2} \mathrm{PO}_{4}\right]^{-},\left[\mathrm{NO}_{3}\right]^{-}\right.$and $\left.\mathrm{I}^{-}\right)$is given in the ESI Section 23.

To identify anionic contributions for $\left[\mathrm{C}_{n} \mathrm{C}_{1} \mathrm{Im}\right][\mathrm{A}] \mathrm{ILs}$ in the region $0 \mathrm{eV}<E_{\mathrm{B}}<11.5 \mathrm{eV}$, the subtracted $[\mathrm{A}]^{-}$traces can be used. To identify anionic contributions for $\left[\mathrm{P}_{6,6,6,14]}\right][\mathrm{A}] \mathrm{ILs}$ in the region $5 \mathrm{eV}<E_{\mathrm{B}}<$ $12 \mathrm{eV},\left[\mathrm{P}_{6,6,6,14}\right] \mathrm{Cl}$ can provide a standard area normalised XP spectrum for subtraction. Cationic $\left[P_{6,6,6,14}\right]^{+}$contributions to the valence $X P$ spectra for $\left[P_{6,6,6,14}\right][A]$ have been identified; in the $p A O$ region they occurred at $4.5 \mathrm{eV}<E_{\mathrm{B}}<12 \mathrm{eV}$ (Section 3.2.4 and Section 3.4.2). Most importantly, there were no significant $\mathrm{Cl}^{-}$contributions in this $E_{\mathrm{B}}$ region, meaning that anionic contributions to valence XP spectra for other $\left[\mathrm{P}_{6,6,6,14}\right][\mathrm{A}]$ ILs can be identified.

For $\left.\left[\mathrm{P}_{6,6,6,14]}\right] \mathrm{N}(\mathrm{CN})_{2}\right]$ the lowest $E_{\mathrm{B}}$ feature was at $2.5 \mathrm{eV}<E_{\mathrm{B}}<4.5 \mathrm{eV}$ (ESI Figure S98a). This feature appeared at significantly lower $E_{\mathrm{B}}$ than the lowest $E_{\mathrm{B}}\left[\mathrm{P}_{6,6,6,14}\right]^{+}$cation contribution at $4.5 \mathrm{eV}<E_{\mathrm{B}}<11.5$ $\mathrm{eV}$ (Section 3.2.4 and Section 3.4.2). For $\left[\mathrm{C}_{4} \mathrm{C}_{1} \mathrm{Im}\right]\left[\mathrm{N}(\mathrm{CN})_{2}\right]$ the lowest $E_{\mathrm{B}}$ anionic feature was at $3 \mathrm{eV}<$ $E_{\mathrm{B}}<5 \mathrm{eV}$ (Figure 10c). This feature appeared at significantly lower $E_{\mathrm{B}}$ than the lowest $E_{\mathrm{B}}\left[\mathrm{C}_{n} \mathrm{C}_{1} 1 \mathrm{~m}\right]^{+}$ 
cation contribution at $4 \mathrm{eV}<E_{\mathrm{B}}<7 \mathrm{eV}$ (Figure 10c). Furthermore, the subtracted trace for $\left[\mathrm{N}(\mathrm{CN})_{2}\right]^{-}$ (i.e. $\left[\mathrm{C}_{4} \mathrm{C}_{1} \mathrm{Im}\right]\left[\mathrm{N}(\mathrm{CN})_{3}\right]$ minus $\left[\mathrm{C}_{8} \mathrm{C}_{1} \mathrm{Im}\right]^{+}$) showed a significant feature at $3 \mathrm{eV}<E_{\mathrm{B}}<5 \mathrm{eV}$ (Figure $10 \mathrm{c}$ ). Therefore, the feature at $3 \mathrm{eV}<E_{\mathrm{B}}<5 \mathrm{eV}$ can be identified as arising from the $\left[\mathrm{N}(\mathrm{CN})_{2}\right]^{-}$anion. In addition, the area normalised valence XP spectra for $\left[\mathrm{P}_{6,6,6,14}\right]\left[\mathrm{N}(\mathrm{CN})_{2}\right]$ and $\left[\mathrm{C}_{4} \mathrm{C}_{1} \mathrm{Im}\right]\left[\mathrm{N}(\mathrm{CN})_{2}\right]$ visually matched well in the region $3 \mathrm{eV}<E_{\mathrm{B}}<4.5 \mathrm{eV}$ (ESI Figure S97b and ESI Figure S98a). The core level $N_{\text {anion }} 1 \mathrm{~s}$ peaks, when charge referenced to $E_{\mathrm{B}}\left(\mathrm{C}_{\text {alkyl }} 1 \mathrm{~s}\right)=285.0 \mathrm{eV}$, for $\left[\mathrm{P}_{6,6,6,14}\right]\left[\mathrm{N}(\mathrm{CN})_{2}\right]$ were at $E_{\mathrm{B}} \sim 0.3$ $\mathrm{eV}$ less than for $\left[\mathrm{C}_{4} \mathrm{C}_{1} \mathrm{Im}\right]\left[\mathrm{N}(\mathrm{CN})_{2}\right]$ (ESI Figure S98b). Therefore, the feature at $2.5 \mathrm{eV}<E_{\mathrm{B}}<4.5 \mathrm{eV}$ for $\left[\mathrm{P}_{6,6,6,14}\right]\left[\mathrm{N}(\mathrm{CN})_{2}\right]$ can be identified as arising from the $\left[\mathrm{N}(\mathrm{CN})_{2}\right]^{-}$anion. As expected, the valence levels due to the $\left[\mathrm{N}(\mathrm{CN})_{2}\right]^{-}$anion were also $E_{\mathrm{B}} \sim 0.3 \mathrm{eV}$ less for $\left[\mathrm{P}_{6,6,6,14}\right]\left[\mathrm{N}(\mathrm{CN})_{2}\right]$ than for $\left[\mathrm{C}_{4} \mathrm{C}_{1} \mathrm{Im}\right]\left[\mathrm{N}(\mathrm{CN})_{2}\right](\mathrm{ESI}$ Figure S98a); when the area normalised valence XP spectrum for $\left[\mathrm{P}_{6,6,6,14}\right]\left[\mathrm{N}(\mathrm{CN})_{2}\right]$ was shifted by $E_{B}$ $+0.3 \mathrm{eV}$ the region $3 \mathrm{eV}<E_{\mathrm{B}}<5 \mathrm{eV}$ visually matched that of $\left[\mathrm{C}_{4} \mathrm{C}_{1} \mathrm{Im}\right]\left[\mathrm{N}(\mathrm{CN})_{2}\right]$ almost perfectly. For $\left[\mathrm{C}_{4} \mathrm{C}_{1} \mathrm{Im}\right][\mathrm{SCN}]$ and $\left[\mathrm{C}_{8} \mathrm{C}_{1} \mathrm{Im}\right]\left[\mathrm{C}(\mathrm{CN})_{3}\right]$ the lowest $E_{\mathrm{B}}$ peaks were at $2.9 \mathrm{eV}$ and $2.8 \mathrm{eV}$ respectively (ESI Figure S87a and Figure 10a), matching the assignment made using variable $h v$ XPS (Section 3.1) and RAES (Section 3.2.2).

For $\left[\mathrm{C}_{8} \mathrm{C}_{1} \mathrm{Im}\right]\left[\mathrm{HSO}_{4}\right],\left[\mathrm{C}_{4} \mathrm{C}_{1} \mathrm{Im}\right]\left[\mathrm{MeSO}_{4}\right],\left[\mathrm{C}_{4} \mathrm{C}_{1} \mathrm{Im}\right]\left[\mathrm{OcSO}_{4}\right],\left[\mathrm{C}_{2} \mathrm{C}_{1} \mathrm{Im}\right]\left[\mathrm{MeSO}_{3}\right]$ and $\left[\mathrm{C}_{4} \mathrm{C}_{1} \mathrm{Im}\right]\left[\mathrm{Me}_{2} \mathrm{PO}_{4}\right]$ gave very visually similar anion traces at $3 \mathrm{eV}<E_{\mathrm{B}}<5 \mathrm{eV}$ (ESI Figure S99b). Therefore, the feature at $3 \mathrm{eV}$ $<E_{\mathrm{B}}<5 \mathrm{eV}$ for $\left[\mathrm{C}_{8} \mathrm{C}_{1} \mathrm{Im}\right]\left[\mathrm{HSO}_{4}\right], \quad\left[\mathrm{C}_{4} \mathrm{C}_{1} \mathrm{Im}\right]\left[\mathrm{MeSO}_{4}\right], \quad\left[\mathrm{C}_{4} \mathrm{C}_{1} \mathrm{Im}\right]\left[\mathrm{OcSO}_{4}\right],\left[\mathrm{C}_{2} \mathrm{C}_{1} \mathrm{Im}\right]\left[\mathrm{MeSO}_{3}\right]$ and $\left[\mathrm{C}_{4} \mathrm{C}_{1} \mathrm{Im}\right]\left[\mathrm{Me}_{2} \mathrm{PO}_{4}\right]$ can be identified as arising from the respective anions. Furthermore, the subtracted traces in the $\mathrm{p} A O$ region for $\left[\mathrm{C}_{4} \mathrm{C}_{1} \mathrm{Im}\right]\left[\mathrm{MeSO}_{4}\right]$ minus $\left[\mathrm{C}_{4} \mathrm{C}_{1} \mathrm{Im}\right]\left[\mathrm{HSO}_{4}\right]$ and $\left[\mathrm{C}_{4} \mathrm{C}_{1} \mathrm{Im}\right]\left[\mathrm{OcSO}_{4}\right]$ minus $\left[\mathrm{C}_{4} \mathrm{C}_{1} \mathrm{Im}\right]\left[\mathrm{HSO}_{4}\right]$ gave little deviation from the zero line (ESI Figure S82b and ESI Figure 82c). However, in the $\mathrm{S} A O$ region at $12 \mathrm{eV}<E_{\mathrm{B}}<24 \mathrm{eV}$ greater deviations were observed than for the $\mathrm{p} A O$ region for data recorded at $h v=1486.6 \mathrm{eV}$ (see ESI Section 23.2 for more discussion). These greater deviations suggest that $\mathrm{CH}_{2}-\mathrm{R}$ groups can have a significant effect on valence electronic structure.

For both $\left[\mathrm{C}_{8} \mathrm{C}_{1} \mathrm{Im}\right]\left[\mathrm{NTf} \mathrm{f}_{2}\right]$ and $\left[\mathrm{C}_{8} \mathrm{C}_{1} \mathrm{Im}\right][\mathrm{TfO}]$, the anion traces showed that the lowest $E_{\mathrm{B}}$ features were at $4 \mathrm{eV}<E_{\mathrm{B}}<7 \mathrm{eV}$ (Figure 10e and ESI Figure S86d). These features arose at approximately the same $E_{\mathrm{B}}$ as the lowest $E_{\mathrm{B}}$ feature due to the $\left[\mathrm{C}_{n} \mathrm{C}_{1} \mathrm{Im}\right]^{+}$cation at $4 \mathrm{eV}<E_{\mathrm{B}}<7 \mathrm{eV}$ (Figure 10e and ESI Figure S86d). Therefore, the features at $4 \mathrm{eV}<E_{\mathrm{B}}<7 \mathrm{eV}$ for $\left[\mathrm{C}_{8} \mathrm{C}_{1} \mid \mathrm{m}\right][\mathrm{TfO}]$ and $\left[\mathrm{C}_{8} \mathrm{C}_{1} \mid \mathrm{m}\right]\left[\mathrm{NTf}_{2}\right]$ were likely to be from both the cation and the anion.

The $\left[\mathrm{BF}_{4}\right]^{-}$anion trace $\left(\left[\mathrm{C}_{8} \mathrm{C}_{1} \mathrm{Im}\right]\left[\mathrm{BF}_{4}\right]\right.$ minus $\left.\left[\mathrm{C}_{8} \mathrm{C}_{1} \mathrm{Im}\right]^{+}\right)$gave a relatively intense feature at $6.5 \mathrm{eV}<E_{\mathrm{B}}<$ $10.5 \mathrm{eV}$; the maximum intensity of the feature was at $E_{\mathrm{B}} \sim 7.8 \mathrm{eV}$ (Figure 10f). Therefore, this feature for $\left[\mathrm{C}_{8} \mathrm{C}_{1} \mathrm{Im}\right]\left[\mathrm{BF}_{4}\right]$ originated from the $\left[\mathrm{BF}_{4}\right]^{-}$anion. Furthermore, at $h v=1486.6 \mathrm{eV}$, the $\mathrm{F} 2 \mathrm{p} \mathrm{AO}$ photoionisation cross-section is 250 times larger than the B $2 p$ AOs photoionisation cross-section (ESI Section 6 and reference ${ }^{37}$ ). Therefore, this feature can be identified as having a significant contribution from the $\mathrm{F}$ atoms in the $\left[\mathrm{BF}_{4}\right]^{-}$anion.

The $\left[B(C N)_{4}\right]^{-}$trace $\left(\left[\mathrm{C}_{6} \mathrm{C}_{1} \mathrm{Im}\right]\left[\mathrm{B}(\mathrm{CN})_{4}\right]\right.$ minus $\left.\left[\mathrm{C}_{8} \mathrm{C}_{1} \mathrm{Im}\right]^{+}\right)$gave a relatively sharp and intense feature at 6 $\mathrm{eV}<E_{\mathrm{B}}<9 \mathrm{eV}$ (Figure 10b). Therefore, this feature can be identified as arising from the $\left[\mathrm{B}(\mathrm{CN})_{4}\right]^{-}$anion. The feature at $6 \mathrm{eV}<E_{\mathrm{B}}<9 \mathrm{eV}$ was the lowest $E_{\mathrm{B}}$ contribution from the $\left[\mathrm{B}(\mathrm{CN})_{4}\right]^{-}$anion. Furthermore, at $h v=1486.6 \mathrm{eV}$, the $\mathrm{N} 2 \mathrm{p}$ and $\mathrm{C} 2 \mathrm{p}$ AO photoionisation cross-sections are $\sim 30$ times and $\sim$ eight times larger than the B $2 p$ AOs photoionisation cross-section respectively (ESI Section 6 and reference ${ }^{37}$ ). Therefore, this feature can be identified as primarily arising from the cyano atoms in the $\left[B(C N)_{4}\right]^{-}$ anion. 


\subsection{Ion HOFO identification}

In this Section, evidence is collated from the previous Sections to highlight when ion HOFO contributions were positively identified. A summary of all $37 \mathrm{ILs}$ is given in Table 3 , and summaries for the seven ILs that were the focus of our RAES study are given in Tables 1 and 2 and ESI Table S8 to ESI Table S12. Furthermore, contributions from ions that were identified for MOs that were at larger $E_{\mathrm{B}}$ than the HOFO are given, where known, in ESI Section 24.

\subsubsection{Cation HOFO identification}

For the four $\left[\mathrm{C}_{n} \mathrm{C}_{1} \mathrm{Im}\right][\mathrm{A}]$ ILs studied here using RAES, the $\mathrm{N}$ 1s and $\mathrm{C}$ 1s RAES data strongly indicated that the cation HOFO was located on the imidazolium ring and not on the alkyl chain (neither butyl nor octyl). Furthermore, variable $h v$ XPS showed that the $\left[C_{n} C_{1} I m\right]^{+}$HOFO had a strong contribution from $p$ AOs. Therefore, it can be concluded that the $\left[\mathrm{C}_{n} \mathrm{C}_{1} \mathrm{Im}\right]^{+}$HOFO (at least for $n \leq 8$ ) was composed of $\mathrm{N} 2 \mathrm{p}$ and $\mathrm{C} 2 \mathrm{p}$ contributions from the imidazolium ring. The $\left[\mathrm{C}_{n} \mathrm{C}_{1} I \mathrm{~m}\right]^{+}$cation HOFO has been assigned to the imidazolium ring based upon DFT calculations for gas phase ion pairs for $\left[\mathrm{C}_{4} \mathrm{C}_{1} \mathrm{Im}\right] \mathrm{Cl}^{72}$ and DFT calculations for eight $\left[\mathrm{C}_{2} \mathrm{C}_{1} \mathrm{Im}\right]\left[\mathrm{B}(\mathrm{CN})_{4}\right]$ ion pairs in the gas phase, ${ }^{73}$ matching our experimental findings. The $\left[\mathrm{C}_{n} \mathrm{C}_{1} \mathrm{Im}\right]^{+}$cation HOFO has been assigned to the imidazolium ring for $\left[\mathrm{C}_{4} \mathrm{C}_{1} \mathrm{Im}\right]^{+}$and to the alkyl chain for $\left[\mathrm{C}_{8} \mathrm{C}_{1} \mathrm{Im}\right]^{+}$and $\left[\mathrm{C}_{10} \mathrm{C}_{1} \mathrm{Im}\right]^{+}$, based upon lone ion gas phase DFT calculations. These conclusions do not match our own; we expect that lone ion gas phase calculations do not account sufficiently for solvation effects.

For $\left[\mathrm{P}_{6,6,6,14}\right]\left[\mathrm{NO}_{3}\right]$, we demonstrated that the cation HOFO had a very significant contribution from $\mathrm{C}$ $2 p$, i.e. alkyl chains; it is possible that the $\mathrm{P} 2 \mathrm{p}$ of the central $\mathrm{P}$ cationic atom contributed to the cation HOFO, but any contribution was likely to be small relative to that of $C 2 p$.

For $\left[\mathrm{N}_{4,1,1,0}\right]\left[\mathrm{HSO}_{4}\right]$ and $\left[\mathrm{N}_{8,8,8,1}\right]\left[\mathrm{NTf}_{2}\right]$, we demonstrated that the cation HOFO had a very significant contribution from $C 2 p$, i.e. alkyl chains (using $C 1$ s RAES data and the subtraction method, respectively); it is possible that the $\mathrm{N} 2 p$ of the central $\mathrm{N}$ cationic atom contributed to the cation HOFO. The cation HOFO was not experimentally identified using methods here for $\left[\mathrm{N}_{2,2,1,0}\right][\mathrm{TfO}]$.

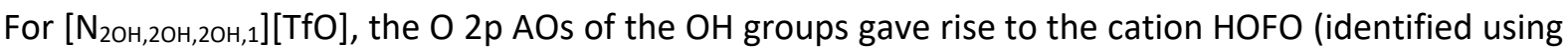
the subtraction method). This finding is in contrast to that for $\left[\mathrm{N}_{4,1,1,0}\right]\left[\mathrm{HSO}_{4}\right]$ and $\left[\mathrm{N}_{8,8,8,1}\right]\left[\mathrm{NTf}_{2}\right]$, where the cation HOFO had a significant contribution from the alkyl chains. Clearly, adding $\mathrm{OH}$ atoms to the cation had a significant effect on the identity of the cation HOFO.

For $\left[S_{2,2, n}\right]\left[\mathrm{NTf}_{2}\right]$, the $\mathrm{S} 3 p$ AOs of the $\left[\mathrm{S}_{2,2, n}\right]^{+}$cations gave rise to the cation HOFO (identified using the subtraction method).

We have been unable to find any previous studies identifying the HOFOs of ILs containing sulfonium cations, ammonium cations, phosphonium cations, or hydroxyl-containing cations.

\subsubsection{Anion HOFO identification}

For the halide anion-based ILs, a combination of variable $h v$ XPS, RAES and the fingerprint method allowed identification of the anion $\mathrm{HOFO}$ as arising from $\mathrm{p} \mathrm{AO}$ contributions, e.g. $\mathrm{Cl} 3 p$ for $\mathrm{Cl}^{-}$. For $\left[\mathrm{C}_{8} \mathrm{C}_{1} \mathrm{Im}\right] \mathrm{Cl}$, Krischok and co-workers used a combination of experiment and DFT calculations to show that the anion HOFO was primarily from $\mathrm{Cl} 3 p .{ }^{39}$ Our identification using variable $h v$ XPS of the cationic contributions to the MOs matched that of Krischok and co-workers. Using variable $h v$ PES (i.e. XPS at $h v=1486.6 \mathrm{eV}$ and UPS) it was shown that the anion HOFO for $\left[\mathrm{C}_{8} \mathrm{C}_{1} \mathrm{Im}\right] \mathrm{Br}$ came from $\mathrm{Br} 4 \mathrm{p},{ }^{19}$ in 
agreement with our findings here. We have been unable to find any identification for HOFOs of ILs containing $\mathrm{l}$.

For both [TfO] $]^{-}$and $\left[\mathrm{NTf}_{2}\right]^{-}$, the anion HOFOs had significant contributions from $\mathrm{O} 2 \mathrm{p} \mathrm{AOs}$, as identified using RAES. For these ILs, contributions to the anion HOFO from other AOs (e.g. F 2p, S 3p, C 2p) could not be ruled out. Ouchi and co-workers used a combination of SXES and calculations to conclude that the anion HOFO for both [TfO] $]^{-}$and $\left[\mathrm{NTf}_{2}\right]^{-}$came from O $2 \mathrm{p},{ }^{18,19}$ matching our conclusions here. Kurisaki and co-workers used a combination of valence XPS and calculations to conclude that the anion $\mathrm{HOFO}$ for $\left[\mathrm{NTf}_{2}\right]^{-}$came from $\mathrm{O} 2 \mathrm{p},{ }^{74}$ matching our conclusions here. Beenken and co-workers used a combination of valence XPS, UPS and calculations to conclude that the anion HOFO for $\left[\mathrm{NTf}_{2}\right]^{-}$came mainly from oxygen, ${ }^{38}$ matching our conclusions here.

The $[\mathrm{SCN}]^{-}$anion HOFO was identified, using a combination of variable $h v \mathrm{XPS}$ and RAES, as having contributions from both $S 3 p$ and $N 2 p$. DFT calculations for eight $\left[C_{2} C_{1} 1 \mathrm{~m}\right][S C N]$ ion pairs in the gas phase (relative to other examples in the literature, this is a very large number of ion pairs used) gave the anion HOFO mainly from $\mathrm{S} 3 p$ and $\mathrm{N} 2 p$ of the $[\mathrm{SCN}]^{-}$anion. ${ }^{73}$ This finding is consistent with our data.

The $\left[\mathrm{C}(\mathrm{CN})_{3}\right]^{-}$anion HOFO had a significant contribution from $\mathrm{N} 2 \mathrm{p}$ of the cyano group. No $\mathrm{C} 2 \mathrm{p}$ contribution to the anion HOFO was identified using $C$ 1s RAES; however, a lack of a peak observed in RAES does not categorically rule out a contribution from the $C 2 p$ of the anion to the anion HOFO. DFT calculations for eight $\left[\mathrm{C}_{2} \mathrm{C}_{1} \mathrm{Im}\right]\left[\mathrm{C}(\mathrm{CN})_{3}\right]$ ion pairs in the gas phase gave the anion HOFO from nitrogen and the central carbon of the $\left[\mathrm{C}(\mathrm{CN})_{3}\right]^{-}$anion. ${ }^{73}$ These findings match our conclusions.

For $\left[\mathrm{B}(\mathrm{CN})_{4}\right]^{-}$, a $\mathrm{N} 2 \mathrm{p}$ AO contribution to the anion HOFOs was identified here, based on observations from a combination of subtracted traces, variable $h v$ XPS and RAES data. DFT calculations for eight $\left[\mathrm{C}_{2} \mathrm{C}_{1} \mathrm{Im}\right]\left[\mathrm{B}(\mathrm{CN})_{4}\right]$ ion pairs in the gas phase showed that the HOFO had a strong contribution from the cyano $\mathrm{N},{ }^{73}$ matching our experimental findings.

For $\left[\mathrm{N}(\mathrm{CN})_{2}\right], \mathrm{AO}$ contributions to the anion HOFO were not identified here, as the AO photoionisation cross-sections for $\mathrm{N} 2 \mathrm{p}$ and $\mathrm{C} 2 \mathrm{p}$ are relatively similar, making identification very challenging using XPS. DFT calculations for eight $\left[\mathrm{C}_{2} \mathrm{C}_{1} \mathrm{Im}\right]\left[\mathrm{N}(\mathrm{CN})_{2}\right]$ ion pairs in the gas phase gave the anion HOFO mainly from $\mathrm{N}$ of the $\left[\mathrm{N}(\mathrm{CN})_{2}\right]^{-}$anion. ${ }^{73}$

The $\left[\mathrm{BF}_{4}\right]^{-}$anion HOFO was identified as having a significant contribution from the $\mathrm{F} 2 \mathrm{p} \mathrm{AOs}$, based upon fingerprint comparisons and $A O$ photoionisation cross-sections. For $\left[C_{n} C_{1} 1 \mathrm{~m}\right]\left[B_{4}\right]$ a combination of UPS and metastable atom electron spectroscopy experiments and lone ion gas phase DFT calculations (using two energy-scale shifts to match the calculated data to the experimental data) identified the anion HOFO as being from $\mathrm{F} 2 \mathrm{p} \mathrm{AOs},{ }^{19,30,75}$ matching our findings.

The $\left[\mathrm{NO}_{3}\right]^{-}$anion HOFO had a significant contribution from $\mathrm{O} 2 \mathrm{p}$, as identified using RAES. Furthermore, there was no significant contribution to the $\left[\mathrm{NO}_{3}\right]^{-}$anion HOFO from N $2 p$, again identified using RAES. For $\left[\mathrm{HSO}_{4}\right]^{-}$the anion HOFO AO contributions was readily identified as $\mathrm{O} 2 \mathrm{p}$ using our RAES data. Given the similarity in spectral shape and relative peak intensity in the HOFO $E_{\mathrm{B}}$ region, as highlighted by data from the subtraction method, for ILs containing $\left[\mathrm{HSO}_{4}\right]^{-},\left[\mathrm{MeSO}_{4}\right]^{-}$, $\left[\mathrm{OcSO}_{4}\right]^{-},\left[\mathrm{MeSO}_{3}\right]^{-}$and $\left[\mathrm{Me}_{2} \mathrm{PO}_{4}\right]^{-}$, we identify the anion HOFO as arising from $\mathrm{O} 2 \mathrm{p}$ contributions for all of these anions. We have been unable to find any identification for HOFOs of ILs containing $\left[\mathrm{HSO}_{4}\right]^{-}$ , $\left[\mathrm{MeSO}_{4}\right]^{-}$, $\left[\mathrm{OcSO}_{4}\right]^{-}$, $\left[\mathrm{MeSO}_{3}\right]^{-},\left[\mathrm{Me}_{2} \mathrm{PO}_{4}\right]^{-}$or $\left[\mathrm{NO}_{3}\right]^{-}$. 


\section{6. $\mathrm{HOMO}$ identification using $E_{\mathrm{B}}$ (ion $\mathrm{HOFO}$ ), $E_{\mathrm{B}}$ (ion onset) and visual inspection}

In this Section results are reported based on two different approaches, $E_{\mathrm{B}}$ (ion $\mathrm{HOFO}$ ) and $E_{\mathrm{B}}$ (ion onset), to quantify the $E_{\mathrm{B}}$ values for cation and anion HOFOs. These values are vital for identifying the IL HOMO, along with visual inspection of the RAE and valence XP spectra. How values for both approaches were determined is outlined in ESI Section 12. $\Delta E_{\mathrm{B}}$ (ion HOFO) $=E_{\mathrm{B}}$ (cation HOFO) $E_{\mathrm{B}}$ (anion HOFO). $E_{\mathrm{B}}$ (ion HOFO) was measured for $34 \mathrm{ILs}$ (Table 3); for $\left[\mathrm{N}_{2,2,1,0}\right][\mathrm{TfO}],\left[\mathrm{N}_{4,1,1,1}\right]\left[\mathrm{NTf}_{2}\right]$ and $\left[\mathrm{N}_{3,2,1,1}\right]\left[\mathrm{NTf}_{2}\right] E_{\mathrm{B}}$ (cation HOFO) were not determined; consequently, $\Delta E_{\mathrm{B}}$ (ion HOFO) could not be obtained for these ILs. $\Delta E_{\mathrm{B}}$ (ion onset) $=E_{\mathrm{B}}$ (cation onset) $-E_{\mathrm{B}}$ (anion onset) was measured for 24 ILs (Table 3); $E_{\mathrm{B}}$ (cation onset) was not measured for nine of the cations $\left(\left[\mathrm{N}_{4,1,1,0}\right]^{+},\left[\mathrm{N}_{8,1,1,0}\right]^{+},\left[\mathrm{P}_{6,6,6,14}\right]^{+}\right.$, $\left[\mathrm{S}_{2,2,2}\right]^{+},\left[\mathrm{S}_{2,2,1}\right]^{+},\left[\mathrm{N}_{2,2,1,0}\right]^{+},\left[\mathrm{N}_{4,1,1,1}\right]^{+},\left[\mathrm{N}_{3,2,1,1}\right]^{+},\left[\mathrm{N}_{8,8,8,1}\right]^{+}$, Table S14), which meant that $\Delta E_{\mathrm{B}}$ (ion onset) could not be measured for 13 ILs. The correlation between $\Delta E_{\mathrm{B}}$ (ion HOFO) and $\Delta E_{\mathrm{B}}$ (ion onset) was excellent. A gradient of 1.01 and an $\mathrm{R}^{2}$ of 0.98 was obtained for a linear correlation (ESI Figure S102).

For 15 ILs studied here (entries 1 to 15 in Table 3), there was no doubt that the anion gave rise to the $\mathrm{HOMO}$, as both $\Delta E_{\mathrm{B}}$ (ion HOFO) and $\Delta E_{\mathrm{B}}$ (ion onset) were positive (larger than the experimental error). For seven ILs studied here (entries 16 to 22 in Table 3 ) both the $\Delta E_{\mathrm{B}}$ (ion HOFO) and $\Delta E_{\mathrm{B}}$ (ion onset) values were positive, but the experimental errors suggested that the cation could give rise to the HOMO. However, additional evidence can be gained by a visual inspection; for all seven of these $\left[\mathrm{C}_{n} \mathrm{C}_{1} \mathrm{Im}\right][\mathrm{A}] \mathrm{IL}$ the anion trace had a feature clearly visible at $E_{\mathrm{B}}$ smaller than the lowest $E_{\mathrm{B}}$ feature for the $\left[\mathrm{C}_{8} \mathrm{C}_{1} \mathrm{Im}\right]^{+}$trace. Therefore, given the weight of evidence that for all seven of these ILs both $\Delta E_{\mathrm{B}}$ (ion $\mathrm{HOFO}$ ) and $\Delta E_{\mathrm{B}}$ (ion onset) were all positive values, and given the visual comparison methods, we conclude that the HOMO was from the anion from these seven ILs. For four ILs studied here (entries 23 to 26 in Table 3) $\Delta E_{\mathrm{B}}$ (ion HOFO) and $\Delta E_{\mathrm{B}}$ (ion onset) were not quantitatively determined; however, given the rationale explained in Section 3.5.1, we can confidently conclude that for these four ILs the HOMO came from the anion. Therefore, for 25 of 37 ILs studied here the anion gave rise to the IL HOMO (Table 3). No $E_{\mathrm{B}}$ (cation HOFO) values were determined for $\left[\mathrm{N}_{2,2,1,0}\right]^{+},\left[\mathrm{N}_{4,1,1,1}\right]^{+}$or $\left[\mathrm{N}_{3,2,1,1}\right]^{+}$. However, we assumed that $E_{B}\left(\right.$ cation HOFO) for $\left[\mathrm{N}_{2,2,1,0}\right]^{+},\left[\mathrm{N}_{4,1,1,1}\right]^{+}$and $\left[\mathrm{N}_{3,2,1,1}\right]^{+}$were similar to $E_{B}$ (cation HOFO) for $\left[\mathrm{N}_{4,1,1,0}\right]^{+}$. Given the significant differences between $E_{B}$ (cation HOFO) for the $\left[\mathrm{N}_{4,1,1,0}\right]^{+}$cation and $E_{\mathrm{B}}$ (anion $\mathrm{HOFO}$ ) for [TfO] $]^{-}$and $\left[\mathrm{NTf}_{2}\right]^{-}$, we positively identified the HOMO as originating from the anion for $\left[\mathrm{N}_{2,2,1,0}\right][\mathrm{TfO}],\left[\mathrm{N}_{4,1,1,1}\right]\left[\mathrm{NTf}_{2}\right]$ and $\left[\mathrm{N}_{3,2,1,1}\right]\left[\mathrm{NTf}_{2}\right]$.

Using experiments, both Ouchi and co-workers and Krischok and co-workers concluded that the halide gave rise to the anion for $\left[C_{8} C_{1} I m\right] B r$ and $\left[C_{n} C_{1} I m\right] C l$ respectively, ${ }^{19,} 39$ in agreement with our findings here. DFT calculations for $\left[\mathrm{C}_{2} \mathrm{C}_{1} \mathrm{Im}\right][\mathrm{SCN}],\left[\mathrm{C}_{2} \mathrm{C}_{1} \mathrm{Im}\right]\left[\mathrm{N}(\mathrm{CN})_{2}\right]$ and $\left[\mathrm{C}_{2} \mathrm{C}_{1} \mathrm{Im}\right]\left[\mathrm{C}(\mathrm{CN})_{3}\right]$ gave the HOMO from the anion. ${ }^{73}$ These findings matched our HOMO identification using a combination of RAES and variable $h v$ XPS. However, we have been unable to find any identification for HOFOs of many of the ILs, e.g. sulfate-containing ILs.

For 10 ILs studied here ([ $\left.\mathrm{C}_{n} \mathrm{C}_{m} \mathrm{Im}\right]\left[\mathrm{NTf} f_{2}\right], \quad\left[\mathrm{P}_{6,6,6,14}\right]\left[\mathrm{NTf}_{2}\right], \quad\left[\mathrm{N}_{8,8,8,1}\right]\left[\mathrm{NTf} f_{2}\right], \quad\left[\mathrm{C}_{n} \mathrm{C}_{1} \mathrm{Im}\right][\mathrm{TfO}]$ and

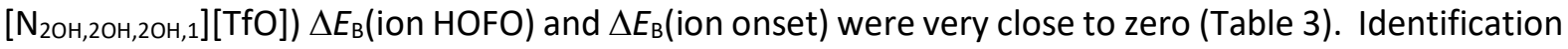
of the HOMO was not possible for these $10 \mathrm{ILs}$, using the experimental data presented here. Using experiments, both Ouchi and co-workers and Beenken and co-workers came to the same conclusion for $\left[\mathrm{C}_{n} \mathrm{C}_{m} \mathrm{Im}\right]\left[\mathrm{NTf}_{2}\right]$. In addition, Slavíček and co-workers found using calculations that for $\left[\mathrm{C}_{n} \mathrm{C}_{1} \mathrm{Im}\right]\left[\mathrm{NTf}_{2}\right](n=2$ and 4$)$ the cation gave rise to the HOMO, although the anion contribution was very close to being the HOMO. ${ }^{76}$

For two ILs studied here $\left(\left[\mathrm{C}_{8} \mathrm{C}_{1} \mathrm{Im}\right]\left[\mathrm{BF}_{4}\right]\right.$ and $\left.\left[\mathrm{C}_{6} \mathrm{C}_{1} \mathrm{Im}\right]\left[\mathrm{B}(\mathrm{CN})_{4}\right]\right) \Delta E_{\mathrm{B}}$ (ion HOFO) and $\Delta E_{\mathrm{B}}$ (ion onset) were both negative, demonstrating that the cation, and not the anion, gave rise to the IL HOMO (Table 3 ). For $\left[C_{n} C_{1} I m\right]\left[B F_{4}\right]$ a combination of UPS and metastable atom electron spectroscopy experiments and lone ion gas phase DFT calculations identified the $\mathrm{HOMO}$ as being from the cation and not the anion. ${ }^{19}$, 
30, 75 These identifications match our identifications using experimental data. For $\left[C_{2} C_{1} I m\right]\left[B(C N)_{4}\right]$, Kötz and co-workers used a combination of XPS experiments and DFT calculations (on a gas phase ion pair) to suggest that the HOMO was not from the $\left[\mathrm{B}(\mathrm{CN})_{4}\right]^{-}$anion. ${ }^{77}$ DFT calculations for eight $\left[\mathrm{C}_{2} \mathrm{C}_{1} \mathrm{Im}\right]\left[\mathrm{B}(\mathrm{CN})_{4}\right]$ ion pairs in the gas phase showed that the HOMO was from the imidazolium ring of the cation and not from the anion. ${ }^{73}$

Table 3. HOFO identities, $\Delta E_{\mathrm{B}}$ (ion onset) $=E_{\mathrm{B}}$ (cation onset) $-E_{\mathrm{B}}$ (anion onset), $\Delta E_{\mathrm{B}}$ (ion HOFO) $=$

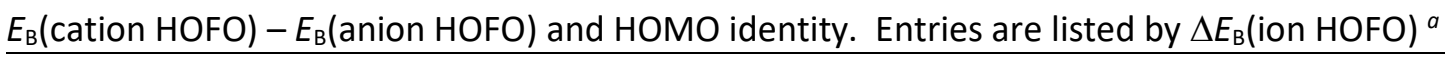

\begin{tabular}{|c|c|c|c|c|c|}
\hline Ionic Liquid & $\begin{array}{l}\text { Cation HOFO } \\
\text { contribution }\end{array}$ & $\begin{array}{l}\text { Anion HOFO } \\
\text { contribution }\end{array}$ & $\begin{array}{l}\Delta E_{\mathrm{B}} \text { (ion onset) / } \\
\mathrm{eV}\end{array}$ & $\begin{array}{l}\Delta E_{\mathrm{B}}(\text { ion HOFO) / } \\
\mathrm{eV}\end{array}$ & HOMO identify \\
\hline$\left[\mathrm{C}_{6} \mathrm{C}_{1} \mathrm{Im}\right] \mathrm{I}$ & $N 2 p+C 2 p$ & $15 p$ & $2.0 \pm 0.5$ & $2.2 \pm 0.5$ & Anion \\
\hline$\left[\mathrm{P}_{6,6,6,14}\right] \mathrm{Br}$ & C $2 p$ & $\operatorname{Br} 4 p$ & Unknown & $2.1 \pm 0.5$ & Anion \\
\hline$\left[\mathrm{N}_{4,1,1,0}\right]\left[\mathrm{HSO}_{4}\right]$ & $C 2 p$ & $02 p$ & Unknown & $2.0 \pm 1.4$ & Anion \\
\hline$\left[\mathrm{N}_{8,1,1,0}\right]\left[\mathrm{HSO}_{4}\right]$ & C $2 p$ & $02 p$ & Unknown & $2.0 \pm 1.4$ & Anion \\
\hline$\left[\mathrm{C}_{8} \mathrm{C}_{1} \mathrm{Im}\right]\left[\mathrm{C}(\mathrm{CN})_{3}\right]$ & $N 2 p+C 2 p$ & $N 2 p$ & $1.9 \pm 0.5$ & $2.0 \pm 0.6$ & Anion \\
\hline$\left[\mathrm{C}_{4} \mathrm{C}_{1} \mathrm{Im}\right][\mathrm{SCN}]$ & $N 2 p+C 2 p$ & $N 2 p+S 3 p$ & $1.8 \pm 0.5$ & $1.9 \pm 0.5$ & Anion \\
\hline$\left[\mathrm{C}_{8} \mathrm{C}_{1} \mathrm{Im}\right][\mathrm{SCN}]$ & $N 2 p+C 2 p$ & $N 2 p+53 p$ & $1.8 \pm 0.5$ & $1.9 \pm 0.5$ & Anion \\
\hline$\left[\mathrm{P}_{6,6,6,14}\right] \mathrm{Cl}$ & C $2 p$ & $\mathrm{Cl} 3 p$ & Unknown & $1.9 \pm 0.5$ & Anion \\
\hline$\left[\mathrm{P}_{6,6,6,14}\right]\left[\mathrm{N}(\mathrm{CN})_{2}\right]$ & C $2 p$ & $\mathrm{~N} 2 \mathrm{p}$ and/or $\mathrm{C} 2 \mathrm{p}$ & Unknown & $1.8 \pm 0.5$ & Anion \\
\hline$\left[\mathrm{C}_{8} \mathrm{C}_{1} \mathrm{Im}\right] \mathrm{Br}$ & $N 2 p+C 2 p$ & $\mathrm{Br} 4 \mathrm{p}$ & $1.5 \pm 0.5$ & $1.6 \pm 0.5$ & Anion \\
\hline$\left[\mathrm{P}_{6,6,6,14}\right]\left[\mathrm{NO}_{3}\right]$ & C $2 p$ & $02 p$ & Unknown & $1.5 \pm 0.5$ & Anion \\
\hline$\left[\mathrm{C}_{4} \mathrm{C}_{1} \operatorname{Im}\right]\left[\mathrm{N}(\mathrm{CN})_{2}\right]$ & $N 2 p+C 2 p$ & $N 2 p$ and/or C $2 p$ & $1.3 \pm 0.6$ & $1.3 \pm 0.8$ & Anion \\
\hline$\left[\mathrm{C}_{8} \mathrm{C}_{1} \mathrm{Im}\right] \mathrm{Cl}$ & $N 2 p+C 2 p$ & $\mathrm{Cl} 3 p$ & $1.1 \pm 0.5$ & $1.1 \pm 0.5$ & Anion \\
\hline$\left[\mathrm{S}_{2,2,2}\right]\left[\mathrm{NTf}_{2}\right]$ & S $3 p$ & All elements & Unknown & $1.0 \pm 0.8$ & Anion \\
\hline$\left[\mathrm{S}_{2,2,1}\right]\left[\mathrm{NTf}_{2}\right]$ & S $3 p$ & All elements & Unknown & $1.0 \pm 0.8$ & Anion \\
\hline$\left[\mathrm{C}_{4} \mathrm{C}_{1} \mathrm{Im}\right]\left[\mathrm{HSO}_{4}\right]$ & $N 2 p+C 2 p$ & $02 p$ & $0.5 \pm 0.6$ & $0.3 \pm 0.8$ & Anion \\
\hline$\left[\mathrm{C}_{8} \mathrm{C}_{1} \mathrm{Im}\right]\left[\mathrm{HSO}_{4}\right]$ & $N 2 p+C 2 p$ & $02 p$ & $0.5 \pm 0.6$ & $0.3 \pm 0.8$ & Anion \\
\hline$\left[\mathrm{C}_{4} \mathrm{C}_{0} \mathrm{Im}\right]\left[\mathrm{HSO}_{4}\right]$ & $N 2 p+C 2 p$ & $02 p$ & $0.3 \pm 0.6$ & $0.3 \pm 0.8$ & Anion \\
\hline$\left[\mathrm{C}_{4} \mathrm{C}_{1} \mathrm{Im}\right]\left[\mathrm{MeSO}_{4}\right]$ & $N 2 p+C 2 p$ & $02 p$ & $0.6 \pm 0.6$ & $0.3 \pm 0.8$ & Anion \\
\hline$\left[\mathrm{C}_{4} \mathrm{C}_{1} \mathrm{Im}\right]\left[\mathrm{OcSO}_{4}\right]$ & $N 2 p+C 2 p$ & $02 p$ & $0.6 \pm 0.6$ & $0.3 \pm 0.8$ & Anion \\
\hline$\left[\mathrm{C}_{2} \mathrm{C}_{1} \mathrm{Im}\right]\left[\mathrm{MeSO}_{3}\right]$ & $N 2 p+C 2 p$ & $02 p$ & $0.7 \pm 0.6$ & $0.3 \pm 0.8$ & Anion \\
\hline$\left[\mathrm{C}_{4} \mathrm{C}_{1} \mathrm{Im}\right]\left[\mathrm{Me}_{2} \mathrm{PO}_{4}\right]$ & $N 2 p+C 2 p$ & $02 p$ & $0.5 \pm 0.6$ & $0.3 \pm 0.8$ & Anion \\
\hline$\left[\mathrm{N}_{2,2,1,0}\right][\mathrm{TfO}]$ & Not identified & $02 p$ & Unknown & Not determined & Anion \\
\hline$\left[\mathrm{N}_{4,1,1,1}\right]\left[\mathrm{NTf}_{2}\right]$ & Not identified & $O 2 p+C 2 p$ & Unknown & Not determined & Anion \\
\hline$\left[\mathrm{N}_{3,2,1,1}\right]\left[\mathrm{NTf}_{2}\right]$ & Not identified & $O 2 p+C 2 p$ & Unknown & Not determined & Anion \\
\hline$\left[\mathrm{C}_{4} \mathrm{C}_{1} \mathrm{Im}\right][\mathrm{TfO}]$ & $N 2 p+C 2 p$ & $O 2 p+C 2 p$ & $0.1 \pm 0.6$ & $-0.2 \pm 0.8$ & Cation/Anion \\
\hline$\left[\mathrm{C}_{8} \mathrm{C}_{1} \mathrm{Im}\right][\mathrm{TfO}]$ & $N 2 p+C 2 p$ & $O 2 p+C 2 p$ & $0.0 \pm 0.6$ & $-0.2 \pm 0.8$ & Cation/Anion \\
\hline$\left[\mathrm{C}_{4} \mathrm{C}_{1} \mathrm{Im}\right]\left[\mathrm{NTf} \mathrm{f}_{2}\right]$ & $N 2 p+C 2 p$ & $O 2 p+C 2 p$ & $-0.1 \pm 0.6$ & $-0.2 \pm 0.8$ & Cation/Anion \\
\hline$\left[\mathrm{C}_{6} \mathrm{C}_{1} \mathrm{Im}\right]\left[\mathrm{NTf} \mathrm{f}_{2}\right]$ & $N 2 p+C 2 p$ & $O 2 p+C 2 p$ & $-0.1 \pm 0.6$ & $-0.2 \pm 0.8$ & Cation/Anion \\
\hline$\left[\mathrm{C}_{8} \mathrm{C}_{1} \mathrm{Im}\right]\left[\mathrm{NTf}_{2}\right]$ & $N 2 p+C 2 p$ & $O 2 p+C 2 p$ & $-0.1 \pm 0.6$ & $-0.2 \pm 0.8$ & Cation/Anion \\
\hline$\left[\mathrm{C}_{2} \mathrm{C}_{0} \mathrm{Im}\right]\left[\mathrm{NTf}_{2}\right]$ & $N 2 p+C 2 p$ & $O 2 p+C 2 p$ & $-0.2 \pm 0.6$ & $-0.2 \pm 0.8$ & Cation/Anion \\
\hline$\left[\mathrm{C}_{4} \mathrm{C}_{0} \mathrm{Im}\right]\left[\mathrm{NTf}_{2}\right]$ & $N 2 p+C 2 p$ & $O 2 p+C 2 p$ & $-0.2 \pm 0.6$ & $-0.2 \pm 0.8$ & Cation/Anion \\
\hline$\left[\mathrm{P}_{6,6,6,14}\right]\left[\mathrm{NTf} f_{2}\right]$ & $C 2 p$ & $O 2 p+C 2 p$ & Unknown & $0.0 \pm 0.8$ & Cation/Anion \\
\hline$\left[\mathrm{N}_{8,8,8,1}\right]\left[\mathrm{NTf}_{2}\right]$ & C $2 p$ & $O 2 p+C 2 p$ & Unknown & $0.0 \pm 0.8$ & Cation/Anion \\
\hline$\left[\mathrm{N}_{2 \mathrm{OH}, 2 \mathrm{OH}, 2 \mathrm{OH}, 1][\mathrm{TfO}]}\right.$ & $02 p$ & $02 p$ & $0.0 \pm 0.6$ & $-0.2 \pm 0.8$ & Cation/Anion \\
\hline$\left[\mathrm{C}_{6} \mathrm{C}_{1} \mathrm{Im}\right]\left[\mathrm{B}(\mathrm{CN})_{4}\right]$ & $N 2 p+C 2 p$ & $N 2 p$ and/or C $2 p$ & $-1.6 \pm 0.6$ & $-1.6 \pm 1.0$ & Cation \\
\hline$\left[\mathrm{C}_{8} \mathrm{C}_{1} \mathrm{Im}\right]\left[\mathrm{BF}_{4}\right]$ & $N 2 p+C 2 p$ & $F 2 p$ & $-2.7 \pm 0.6$ & $-2.8 \pm 1.0$ & Cation \\
\hline
\end{tabular}

${ }^{a}$ The HOMO identity assignments for $\left[\mathrm{N}_{2,2,1,0}\right][\mathrm{TfO}],\left[\mathrm{N}_{4,1,1,1}\right]\left[\mathrm{NTf}_{2}\right]$ and $\left[\mathrm{N}_{3,2,1,1}\right]\left[\mathrm{NTf}_{2}\right]$ were based upon a combination of $E_{\mathrm{B}}$ (anion HOFO) for these ILs and $E_{\mathrm{B}}$ (cation HOFO) for $\left[\mathrm{N}_{4,1,1,0}\right]\left[\mathrm{HSO}_{4}\right]$ 


\section{Conclusions}

Using experimental data from a combination of resonant Auger electron spectroscopy (RAES) and Xray photoelectron spectroscopy (XPS), we have identified cation and anion highest occupied fragment orbitals (HOFOs) for 37 ILs. Furthermore, we have determined the energies of these cation and anion HOFOs, which has allowed us to identify the highest occupied molecular orbital (HOMO) for each IL. The HOMO was clearly from the anion for most ILs studied here ( 25 out of a total of 37 ILs studied). For 10 of the ILs, the cation and anion HOFO energies were the same within the error of the experimental measurements, meaning that the HOMO could not be identified for these 10 ILs. For two of the ILs the cation was clearly the HOMO, a remarkable finding - it is energetically more favourable to remove an electron from the positively charged cation than the negatively charged anion.

In this paper, we have introduced three new experimental approaches for identifying atomic orbital contributions to the valence electronic structure of ILs. RAES is an incredibly powerful technique for ILs; it can provide experimental identification of MOs, without the need for input from calculations. The results for $\left[\mathrm{C}_{4} \mathrm{C}_{1} \mathrm{Im}\right][\mathrm{SCN}]$ and $\left[\mathrm{C}_{8} \mathrm{C}_{1} \mathrm{Im}\right]\left[\mathrm{C}(\mathrm{CN})_{3}\right]$ show that RAES is especially effective for distinguishing the cationic and anionic contributions for the same element, in this case nitrogen. Both comparison methods, the fingerprint method and the subtraction method, have proven effective for identification of MOs for a range of different IL structures, in particular when used as a complementary method to information provided by RAES. Both the fingerprint and subtraction methods worked well for identification of contributions from elements with relatively large photoionisation cross-sections at the $h v$ used, e.g. at $h v=1486.6 \mathrm{eV} \mathrm{S} 3 p$ contributions were identified for $\left[\mathrm{S}_{2,2,2}\right]\left[\mathrm{NTf}_{2}\right]$, but C $2 p$ contributions can be hard to identify. In addition, ILs with larger molecular units, e.g. $\left[\mathrm{N}_{8,8,8,1}\right]^{+}$, gave relatively intense contributions compared to ILs with smaller molecular units, e.g. $\left[\mathrm{N}_{2,2,1,0}\right]^{+}$, making MO identification easier for these ILs with larger molecular units. In total, we have used the subtraction method to obtain traces for 10 cations and 14 anions.

The unambiguous experimental identification of elemental contributions to the HOFOs and HOMOs is expected to be very useful for understanding different forms of reactivity data, e.g. the origin of oxidative and reductive stability. Moreover, it provides an invaluable piece of experimental information for the validation of IL calculations. Experimental identification of the HOMO for ILs, without contributions from calculations, is very limited to date. Most calculations for ILs, e.g. those of the electronic structure, are usually performed on relatively small numbers of ions. Therefore, this comprehensive data set will be particularly valuable to evaluate if calculations capture ion solvation correctly. 


\section{Acknowledgements}

KRJL acknowledges Imperial College London for the award of a Junior Research Fellowship and the Royal Society for the award of a University Research Fellowship. The authors acknowledge the EPSRC for the award of a DTA studentship (RMF). We thank Dr. Agnieszka Brandt-Talbot, Dr. Heiko Niedermeyer, Dr. Claire Ashworth, Dr. Nur Ismail and Dr. Tom Vander Hoogerstraete for IL synthesis. This work was carried out with the support of MAX-lab, 1311. We would like to express our thanks to the staff of MAX-lab for their technical assistance, especially Dr. Jacek Osiecki. We thank Dr. Alexei Preobrajenski for sharing his RAES data for $\mathrm{Na}\left[\mathrm{NO}_{3}\right]$.

\section{References}

1. I. Fleming, Molecular Orbitals and Organic Chemical Reactions, Wiley, Chichester, 2010.

2. K. Fukui, Angew. Chem.-Int. Edit. Engl., 1982, 21, 801-809.

3. R. Hoffmann, Angew. Chem.-Int. Edit. Engl., 1982, 21, 711-724.

4. P. Hapiot and C. Lagrost, Chem. Rev., 2008, 108, 2238-2264.

5. M. Armand, F. Endres, D. R. MacFarlane, H. Ohno and B. Scrosati, Nat. Mater., 2009, 8, 621629.

6. D. R. MacFarlane, N. Tachikawa, M. Forsyth, J. M. Pringle, P. C. Howlett, G. D. Elliott, J. H. Davis, M. Watanabe, P. Simon and C. A. Angell, Energy Environ. Sci., 2014, 7, 232-250.

7. D. R. MacFarlane, M. Forsyth, P. C. Howlett, M. Kar, S. Passerini, J. M. Pringle, H. Ohno, M. Watanabe, F. Yan, W. J. Zheng, S. G. Zhang and J. Zhang, Nat. Rev. Mater., 2016, 1, 15005.

8. C. Nese and A. N. Unterreiner, Phys. Chem. Chem. Phys., 2010, 12, 1698-1708.

9. E. W. Castner, C. J. Margulis, M. Maroncelli and J. F. Wishart, Annu. Rev. Phys. Chem., 2011, 62, 85-105.

10. X. Q. Sun, H. M. Luo and S. Dai, Chem. Rev., 2012, 112, 2100-2128.

11. A. Brandt, J. Gräsvik, J. P. Hallett and T. Welton, Green Chem., 2013, 15, 550-583.

12. Y. F. Hu, Z. C. Liu, C. M. Xu and X. M. Zhang, Chem. Soc. Rev., 2011, 40, 3802-3823.

13. X. P. Zhang, X. C. Zhang, H. F. Dong, Z. J. Zhao, S. J. Zhang and Y. Huang, Energy Environ. Sci., 2012, 5, 6668-6681.

14. V. R. Koch, L. A. Dominey, C. Nanjundiah and M. J. Ondrechen, J. Electrochem. Soc., 1996, 143, 798-803.

15. P. Ballone and R. Cortes-Huerto, Faraday Discuss., 2012, 154, 373-389.

16. K. L. Van Aken, M. Beidaghi and Y. Gogotsi, Angew. Chem.-Int. Edit., 2015, 54, 4806-4809.

17. T. Nishi, T. Iwahashi, H. Yamane, Y. Ouchi, K. Kanai and K. Seki, Chem. Phys. Lett., 2008, 455, 213-217.

18. K. Kanai, T. Nishi, T. Iwahashi, Y. Ouchi, K. Seki, Y. Harada and S. Shin, J. Chem. Phys., 2008, 129, 224507.

19. K. Kanai, T. Nishi, T. Iwahashi, Y. Ouchi, K. Seki, Y. Harada and S. Shin, J. Electron Spectrosc. Relat. Phenom., 2009, 174, 110-115.

20. A. Ulbrich, M. Reinmöller, W. J. D. Beenken and S. Krischok, J. Mol. Liq., 2014, 192, 77-86.

21. K. R. J. Lovelock, I. J. Villar-Garcia, F. Maier, H. P. Steinrück and P. Licence, Chem. Rev., 2010, 110, 5158-5190.

22. R. Seidel, S. Thurmer and B. Winter, J. Phys. Chem. Lett., 2011, 2, 633-641.

23. N. Ottosson, G. Öhrwall and O. Björneholm, Chem. Phys. Lett., 2012, 543, 1-11.

24. M. A. Brown, M. Faubel and B. Winter, Annu. Rep. Prog. Chem., Sect. C, 2009, 105, 174-212.

25. R. Seidel, B. Winter and S. E. Bradforth, Annu. Rev. Phys. Chem., 2016, 67, 283-305.

26. B. Winter and M. Faubel, Chem. Rev., 2006, 106, 1176-1211.

27. B. Winter, Nucl. Instrum. Methods Phys. Res. Sect. A-Accel. Spectrom. Dect. Assoc. Equip., 2009, 601, 139-150.

28. T. Fransson, Y. Harada, N. Kosugi, N. A. Besley, B. Winter, J. J. Rehr, L. G. M. Pettersson and A. Nilsson, Chem. Rev., 2016, 116, 7551-7569.

29. S. Kuwabata, T. Tsuda and T. Torimoto, J. Phys. Chem. Lett., 2010, 1, 3177-3188. 
30. D. Yoshimura, T. Yokoyama, T. Nishi, H. Ishii, R. Ozawa, H. Hamaguchi and K. Seki, J. Electron Spectrosc. Relat. Phenom., 2005, 144, 319-322.

31. S. Krischok, R. Öttking, W. J. D. Beenken, M. Himmerlich, P. Lorenz, O. Höfft, S. Bahr, V. Kempter and J. A. Schaefer, Z. Phys. Chemie-Int. J. Res. Phys. Chem. Chem. Phys., 2006, 220, 1407-1416.

32. S. Krischok, M. Eremtchenko, M. Himmerlich, P. Lorenz, J. Uhlig, A. Neumann, R. Öttking, W. J. D. Beenken, O. Höfft, S. Bahr, V. Kempter and J. A. Schaefer, J. Phys. Chem. B, 2007, 111, 4801-4806.

33. S. Men, K. R. J. Lovelock and P. Licence, Phys. Chem. Chem. Phys., 2011, 13, 15244-15255.

34. S. Men, D. S. Mitchell, K. R. J. Lovelock and P. Licence, ChemPhysChem, 2015, 16, 2211-2218.

35. U. Gelius and K. Siegbahn, Faraday Discuss., 1972, 54, 257-268.

36. U. Gelius, J. Electron Spectrosc. Relat. Phenom., 1974, 5, 985-1057.

37. J. J. Yeh and I. Lindau, At. Data Nucl. Data Tables, 1985, 32, 1-155.

38. M. Reinmöller, A. Ulbrich, T. Ikari, J. Preiss, O. Höfft, F. Endres, S. Krischok and W. J. D. Beenken, Phys. Chem. Chem. Phys., 2011, 13, 19526-19533.

39. A. Ulbrich, M. Reinmöller, W. J. D. Beenken and S. Krischok, ChemPhysChem, 2012, 13, 17181724.

40. T. Tiedje, K. M. Colbow, D. Rogers and W. Eberhardt, Phys. Rev. Lett., 1990, 65, 1243-1246.

41. A. B. Preobrajenski, A. S. Vinogradov and N. Mårtensson, J. Electron Spectrosc. Relat. Phenom., 2005, 148, 59-64.

42. A. B. Preobrajenski, A. S. Vinogradov, S. L. Molodtsov, S. K. Krasnikov, T. Chasse, R. Szargan and C. Laubschat, Phys. Rev. B, 2002, 65, 205116.

43. A. B. Preobrajenski, A. S. Vinogradov, S. L. Molodtsov, S. A. Krasnikov, R. Szargan and C. Laubschat, Chem. Phys. Lett., 2003, 368, 125-131.

44. R. Dudde, M. L. M. Rocco, E. E. Koch, S. Bernstorff and W. Eberhardt, J. Chem. Phys., 1989, 91, 20-28.

45. M. Mauerer, P. Zebisch, M. Weinelt and H. P. Steinrück, J. Chem. Phys., 1993, 99, 3343-3352.

46. E. E. Rennie, U. Hergenhahn, O. Kugeler, A. Rüdel, S. Marburger and A. M. Bradshaw, J. Chem. Phys., 2002, 117, 6524-6532.

47. W. Wurth and D. Menzel, J. Electron Spectrosc. Relat. Phenom., 1993, 62, 23-31.

48. D. Menzel, G. Rocker, H. P. Steinrück, D. Coulman, P. A. Heimann, W. Huber, P. Zebisch and D. R. Lloyd, J. Chem. Phys., 1992, 96, 1724-1734.

49. J. J. Gallet, F. Bournel, S. Kubsky, G. Dufour, F. Rochet and F. Sirotti, J. Electron Spectrosc. Relat. Phenom., 2002, 122, 285-295.

50. W. Osikowicz, R. Friedlein, M. P. de Jong, S. L. Sorensen, L. Groenendaal and W. R. Salaneck, New J. Phys., 2005, 7, 104.

51. R. Friedlein, S. L. Sorensen, A. Baev, F. Gel'mukhanov, J. Birgerson, A. Crispin, M. P. de Jong, W. Osikowicz, C. Murphy, H. Agren and W. R. Salaneck, Phys. Rev. B, 2004, 69, 125204.

52. J. Kikuma and B. P. Tonner, J. Electron Spectrosc. Relat. Phenom., 1996, 82, 41-52.

53. J. J. Gallet, F. Jolly, F. Rochet, F. Bournel, G. Dufour, P. A. Avila, F. Sirotti and P. Torelli, J. Electron Spectrosc. Relat. Phenom., 2002, 122, 11-25.

54. D. V. Vyalikh, V. V. Maslyuk, A. Bluher, A. Kade, K. Kummer, Y. S. Dedkov, T. Bredow, I. Mertig, M. Mertig and S. L. Molodtsov, Phys. Rev. Lett., 2009, 102, 098101.

55. Y. Baba, T. Sekiguchi, I. Shimoyama, N. Hirao and K. G. Nath, Phys. Rev. B, 2006, 74, 205433.

56. H. S. Kato, M. Furukawa, M. Kawai, M. Taniguchi, T. Kawai, T. Hatsui and N. Kosugi, Phys. Rev. Lett., 2004, 93, 086403.

57. B. Winter, U. Hergenhahn, M. Faubel, O. Björneholm and I. V. Hertel, J. Chem. Phys., 2007, 127, 094501.

58. M. Kot, K. Wojciechowski, H. Snaith and D. Schmeisser, Chem.-Eur. J., 2018, 24, 3539-3544.

59. B. Winter, E. F. Aziz, N. Ottosson, M. Faubel, N. Kosugi and I. V. Hertel, J. Am. Chem. Soc., 2008, 130, 7130-7138. 
60. S. Thurmer, R. Seidel, W. Eberhardt, S. E. Bradforth and B. Winter, J. Am. Chem. Soc., 2011, 133, 12528-12535.

61. R. Seidel, K. Atak, S. Thurmer, E. F. Aziz and B. Winter, J. Phys. Chem. B, 2015, 119, 1060710615.

62. R. Golnak, S. I. Bokarev, R. Seidel, J. Xiao, G. Grell, K. Atak, I. Unger, S. Thurmer, S. G. Aziz, O. Kuhn, B. Winter and E. F. Aziz, Sci Rep, 2016, 6, 24659.

63. S. S. N. Lalithambika, K. Atak, R. Seidel, A. Neubauer, T. Brandenburg, J. Xiao, B. Winter and E. F. Aziz, Sci Rep, 2017, 7, 40811.

64. J. W. Smith and R. J. Saykally, Chem. Rev., 2017, 117, 13909-13934.

65. R. M. Fogarty, R. P. Matthews, C. R. Ashworth, A. Brandt-Talbot, R. G. Palgrave, R. A. Bourne, T. V. Hoogerstraete, P. A. Hunt and K. R. J. Lovelock, J. Chem. Phys., 2018, 148, 193817.

66. R. M. Fogarty, R. Rowe, R. P. Matthews, M. T. Clough, C. R. Ashworth, A. Brandt, P. J. Corbett, R. G. Palgrave, E. F. Smith, R. A. Bourne, T. W. Chamberlain, P. B. J. Thompson, P. A. Hunt and K. R. J. Lovelock, Faraday Discuss., 2018, 206, 183-201.

67. J. M. Thomas, I. Adams and M. Barber, Solid State Commun., 1971, 9, 1571-1573.

68. R. M. Fogarty, R. P. Matthews, M. T. Clough, C. R. Ashworth, A. Brandt-Talbot, P. J. Corbett, R. G. Palgrave, R. A. Bourne, T. W. Chamberlain, T. Vander Hoogerstraete, P. B. J. Thompson, P. A. Hunt, N. A. Besley and K. R. J. Lovelock, Phys. Chem. Chem. Phys., 2017, 19, 3115631167.

69. F. Rodrigues, D. Galante, G. M. do Nascimento and P. S. Santos, J. Phys. Chem. B, 2012, 116, 1491-1498.

70. C. Ehlert, M. Holzweber, A. Lippitz, W. E. S. Unger and P. Saalfrank, Phys. Chem. Chem. Phys., 2016, 18, 8654-8661.

71. Y. Horikawa, T. Tokushima, O. Takahashi, H. Hoke and T. Takamuku, J. Phys. Chem. B, 2016, 120, 7480-7487.

72. P. A. Hunt, B. Kirchner and T. Welton, Chem.-Eur. J., 2006, 12, 6762-6775.

73. K. B. Dhungana, L. F. O. Faria, B. N. Wu, M. Liang, M. C. C. Ribeiro, C. J. Margulis and E. W. Castner, J. Chem. Phys., 2016, 145, 024503.

74. T. Kurisaki, D. Tanaka, Y. Inoue, H. Wakita, B. Minofar, S. Fukuda, S. Ishiguro and Y. Umebayashi, J. Phys. Chem. B, 2012, 116, 10870-10875.

75. T. Iwahashi, T. Nishi, H. Yamane, T. Miyamae, K. Kanai, K. Seki, D. Kim and Y. Ouchi, J. Phys. Chem. C, 2009, 113, 19237-19243.

76. L. Šištík, M. Ončák and P. Slavíček, Phys. Chem. Chem. Phys., 2011, 13, 11998-12007.

77. D. Weingarth, I. Czekaj, Z. F. Fei, A. Foelske-Schmitz, P. J. Dyson, A. Wokaun and R. Kötz, J. Electrochem. Soc., 2012, 159, H611-H615. 